NBER WORKING PAPER SERIES

\title{
COMPUTERIZATION AND IMMIGRATION: THEORY AND EVIDENCE FROM THE UNITED STATES
}

\author{
Gaetano Basso \\ Giovanni Peri \\ Ahmed Rahman \\ Working Paper 23935 \\ http://www.nber.org/papers/w23935 \\ NATIONAL BUREAU OF ECONOMIC RESEARCH \\ 1050 Massachusetts Avenue \\ Cambridge, MA 02138 \\ October 2017, Revised October 2018
}

We want to thank Matteo Bugamelli, Francesca Carta, Federico Cingano, Francesco D'Amuri, Andrea Linarello, Francesca Mazzolari, Chad Sparber, Shyam Gouri Suresh, Eliana Viviano and numerous participants at seminars at the Bank of Italy, CIRET-Università La Sapienza (Roma), ZEW (Mannheim), Lehigh University, Barnard College, the AIEL 2017 Conference, the Macroeconomics for Liberal Arts Colleges workshop at Davidson College, and the Society for Labor Economists meetings in Toronto, for their insightful comments. The views expressed in the paper are those of the authors only and do not reflect the opinion of the Bank of Italy nor those of the National Bureau of Economic Research. We did not receive any funding for this project.

NBER working papers are circulated for discussion and comment purposes. They have not been peer-reviewed or been subject to the review by the NBER Board of Directors that accompanies official NBER publications.

(C) 2017 by Gaetano Basso, Giovanni Peri, and Ahmed Rahman. All rights reserved. Short sections of text, not to exceed two paragraphs, may be quoted without explicit permission provided that full credit, including $(\odot$ notice, is given to the source. 
Computerization and Immigration: Theory and Evidence from the United States

Gaetano Basso, Giovanni Peri, and Ahmed Rahman

NBER Working Paper No. 23935

October 2017, Revised October 2018

JEL No. J15,J24,O15,O33

\begin{abstract}
$\underline{\text { ABSTRACT }}$
Recent technological changes have been characterized as "routine-substituting," reducing demand for routine tasks but increasing it for analytical and service tasks. Little is known about how these changes have impacted immigration, or task specialization between immigrants and natives. In this paper we show that such technological progress has been an important determinant of immigration, attracting immigrants who increasingly specialize in manual-service occupations. We also suggest that open- ness to immigration attenuated job and wage polarization for natives resulting from technological changes. We explain these facts with a model of technological progress and endogenous immigration. Simulations show that unskilled immigration attenuates the drop in routine employment proceeding from technological change, enhances skill-upgrading for natives, and raises economy-wide productivity and welfare.
\end{abstract}

Gaetano Basso

Directorate General for Economics, Statistics and Research

Bank of Italy

Via Nazionale 91

00184 Rome

Italy

gaetano.basso@bancaditalia.it

Giovanni Peri

Department of Economics

University of California, Davis

One Shields Avenue

Davis, CA 95616

and NBER

gperi@ucdavis.edu

\author{
Ahmed Rahman \\ Department of Economics \\ 589 McNair Road \\ Annapolis, MD 21402 \\ United States \\ rahman@usna.edu
}




\section{Introduction}

The automation and computerization of many tasks in the production process during the last few decades have generated important effects on US labor markets. First, this type of technological change has contributed to the decline of the employment share of workers performing routine-intensive tasks, as those were increasingly performed by computers (Autor, Levy and Murnane, 2003; Goos, Manning and Salomon, 2014). Second, it has simultaneously contributed to the increase in the employment shares of cognitive-intensive occupations whose productivity and demand were enhanced by computers. Finally, it has fostered stability or a mild increase in the employment shares of workers performing manual and non-routine-intensive jobs in the service sector (see Autor, 2011). As routine-intensive jobs tend to occupy the middle-range of the earnings distribution, while manual-intensive jobs cluster near the bottom and cognitive intensive jobs cluster near the top, this phenomenon during the last three decades has contributed to what has been called the "polarization" of the labor market. ${ }^{1}$

Within this context, we ask two sets of questions about which very little is known. First, did foreign workers (immigrants) respond to these shifts in labor demand more than native workers, so that the increase in their share (particularly in the faster growing segments of the labor market) experienced in the last three decades was driven in part by this phenomenon? And, within the United States, did immigrants concentrate in those labor markets where computerization occurred at faster rates? The focus on immigrants in the U.S. is interesting because they exhibit a distribution of skills quite distinct from U.S. natives (Peri, 2008). Particularly among the less educated, they specialize in manual-intensive service occupations (such as house-keeping, building, gardening, baby-sitting), and their supply may have been particularly responsive to these routine-substituting technological changes. ${ }^{2}$ Moreover, as already emphasized by Cadena and Kovak (2016), less educated immigrants seem to respond more to differential labor demand shocks than native workers at the local level. This was shown for short-term shocks; here we analyze whether this was true for longer-run technology-

\footnotetext{
${ }^{1}$ The decribed distribution of occupations over the wage range reflects their relative position in the 1980's which is still largely persistent. Continued decline in the demand for routine jobs, however, may eventually alter their relative position in the wage range.

${ }^{2}$ See Peri and Sparber (2009).
} 
driven demand changes. ${ }^{3}$

Second, did the differential inflow of immigrants in local US labor markets affect the extent of employment polarization for natives? Namely, did the employment impact of computerization on natives differ if we account for the impact on the immigrant population? Immigrants tend to specialize in manual service jobs at the lower end of the skill spectrum, and demand growth in the 1980-2010 period was especially intensive for this segment of the labor market. One might suspect that migrants responding to technological changes with a higher "elasticity of supply" than natives produced a complementary effect on natives, attenuating their outflow from routine jobs and encouraging their joining analytical ones.

In our empirical analysis we first test how immigration responded to the introduction of personal computers, the most creative/disruptive and diffused of the technologies introduced between 1980 and 2010 (Autor et al., 2003; Beaudry, Doms and Lewis, 2010). To do so we construct a proxy that captures the local diffusion of PCs in the spirit of the one introduced by Autor et al. (2003). Differently from them, we distribute the nationwide industry adoption of PCs across local labor markets using as weights the industry employment share in each commuting zone $(\mathrm{CZ})$ as of 1980 . This is a novel way to capture the idea that a locality with a large employment share in industries which experienced robust computer-adoption were subject to larger changes in occupational and productive structure and hence in skill demand. We will often call this variable simply "computerization."

To validate our novel measure, we test its correlation with existing proxies used to measure the predicted intensity of local de-routinization - the measure of local routine-intensity as defined by Autor and Dorn (2013) - and computerization - the adoption of PCs by firms (Beaudry et al., 2010). We then analyze its correlation with employment changes for highand low-skilled natives and immigrants. We establish that computerization intensity across local labor markets in the US is strongly associated with both high-skilled and low-skilled immigration over the decades 1980-2010. This is much less so for internal migration of low-skilled natives, indicating that foreign-born immigrants tend to respond to the adoption of automating technology more than natives. We also show that immigrants, contrary to

\footnotetext{
${ }^{3}$ The highly educated among immigrants specialize in science, technology and engineering jobs. Also their inflow has grown significantly in the recent decades.
} 
natives, tend to increasingly specialize over time in manual intensive jobs. Regression-based evidence confirms this result. The local intensity of computerization is associated with increases in native employment in analytical-intensive jobs, decreases in routine jobs, and no change in manual employment. However, novel to this paper, we also show that immigrants in areas with large computer adoption tend to experience a substantial growth in manual service-oriented employment. This implies that a larger immigrant supply response in localities of fast computer adoption filled manual-occupation demand, reducing the displacement of natives from routine to manual and hence reducing their "downgrading." Further, the complementarity between manual and routine jobs increased demand for mid-skills and kept some natives in routine positions, offsetting some of the polarizing effects of technology. The interesting new implications of these empirical results are that, in the presence of endogenous immigration responding to economic incentives (i) the employment- and wage-polarizing effects of computerization on native workers are attenuated, (ii) much, if not all the rise in the lower end polarization curve of Autor and Dorn (2013) is attributable to foreign born. Indeed, we see that the majority of service workers contributing to low-end employment polarization are in fact migrants, and their presence generates more local demand for routine, mid-skilled jobs. Conceivably without them mid-skilled natives would be more prone to employment and wage losses.

In the second part of the paper, we develop a model that shows more rigorously what framework is needed to produce such effects of computerization and endogenous immigration on native polarization. The model extends Autor and Dorn (2013). In that framework, the acceleration of computerization is the cause of change in demand for routine labor, and the complementarity between goods (routine intensive) and services (non-routine, manual intensive) produces the polarization of employment, with low skilled workers moving from good to service production. The crucial novelty of our model is that we allow for endogenous inflows of immigrants, focusing on the low-skilled ones. ${ }^{4}$ We then analyze how computerization coupled with endogenous migration affects the employment of natives. We compare a baseline case when immigrant supply responds moderately to computerization with a case where no immigrants are allowed in the country. These comparisons provide a reasonable

\footnotetext{
${ }^{4}$ In an extension we allow also immigration of high skilled immigrants.
} 
quantitative explanation for the key findings of our empirical analysis. Immigrant supply and their specialization in manual tasks attenuates the negative impact of technology on routine employment of natives, while at the same time raises the demand for analytical tasks. Allowing stronger immigrant response would reduce further the polarization effect of computerization on native jobs and wages at the low end of the wage spectrum. Further, the model demonstrates that under a wide range of parameter values, low-skilled migration boosts aggregate welfare for natives, as the gains from skill enhancement and productivity more than offset the pecuniary losses to natives who remain as service workers.

The rest of the paper proceeds as follows. We review the relevant literature in Section 2. Then in Section 3 we present some empirical facts and estimate some correlations across local labor markets. In Section 4 we develop a model that provides intuition for the main findings and we discuss the simulation results. In section 5 we conclude the paper.

\section{Literature Review}

This paper stands at the intersection of two strands of literature. On one hand it contributes to our understanding of how computerization affected job and wage polarization by exploring the lesser known impacts from immigrants' labor supply and task specialization. On the other hand it complements the literature on the labor market impacts of immigration, particularly as it has focused on the differences between native and immigrant workers (Ottaviano and Peri, 2012), identifying task specialization (Peri and Sparber, 2009) and technological adoption (Lewis, 2013) as important dimensions responding to changes in immigrant supply.

To explain the relatively poor employment (and wage) growth in the middle of the skill distribution during the 1990's and 2000's, several recent papers (notably Autor and Dorn, 2013; Acemoglu and Autor, 2011; Goos, Salomon and Manning, 2014; Acemoglu and Restrepo, 2017) have shown that computer-intensive technological growth has eroded the demand for routine-jobs. These used to be relatively well paid occupations squarely in the middle of the earnings distribution. Machines and computers have substituted many of the "routine-tasks" performed by workers. On the other hand they have enhanced the productivity of analytical (also labeled as "cognitive" or "complex") jobs (see Autor, 2015 for a 
detailed explanation of these effects). This helps explain the increase in inequality at the top of the wage distribution. Finally, computerization has not much affected the physical productivity of manual-intensive jobs in services (e.g. cooking, house keeping, baby-sitting, health care, food, landscaping). However, the demand for those services may have increased because they complement the consumption of goods and services produced using computers. This may have driven polarization in the lower part of the wage spectrum (see Autor and Dorn, 2013). ${ }^{5}$

New in this literature, we extend the analysis of the consequences of automating technology adoption on two dimensions. First, related to findings in Cadena and Kovak (2016) and Borjas (2001), who show large short-run responses of immigrants to local labor demand shocks, we document a strong response of immigrants to computer adoption at the commuting zone level. Particularly interesting is the response of less skilled immigrants to areas with fast PC-use growth. Second, building on the fact that low-skilled immigrants supply manual-tasks more intensely than natives, we are the first (to our knowledge) to notice that automating technology produced less employment transition of native workers from routine to manual jobs. While the small (and sometimes positive) association of low skilled immigration with employment and wages of native workers has been known for some time (Card, 2001; Card, 2009; Basso and Peri, 2015), we are the first to propose an explanation based on technological growth and specialization. As automation has depressed routine-job demand and pushed workers from intermediate wage jobs to low paid manual jobs, immigration has pushed in the opposite direction by increasing the relative demand for routine jobs performed by natives. Such an attenuating factor may have helped reverse the tendency of less skilled natives to move to lower paid manual jobs.

Our paper complements a series of recent papers that have analyzed the role of high skilled immigrants within the context of innovation and technological change (Bound et al., 2018, Jaimovich and Siu, 2018; Waugh, 2018). These papers focus on the role of highly skilled immigrants, who are predominantly employed in science and technology, and analyze

\footnotetext{
${ }^{5} \mathrm{~A}$ recent paper by Cerina et al. (2017) argues that women are the main driver of both low and high-end polarization. Our work is complementary to Cerina et al., in that we look at the importance of low-skilled immigrants in driving the growth in service occupations, and we analyze how, in turn, this affects native occupational upgrading.
} 
long-run outcomes in the presence of technological innovation enhanced by high skilled immigrants. These studies (especially Bound et al., 2018; and Jaimovich and Siu, 2018) also explicitly model the fact that highly skilled immigrants have a strong preference for occupations in the computer sector which can further enhances innovation. While we focus on unskilled immigrants, and document a less known complementarity between computerization and this group, these papers share with our approach the emphasis on task specialization between immigrants and similarly educated natives, and the benefits that this may generate for natives. ${ }^{6}$

Finally, our paper is further related to, yet substantially different from, the literature on directed skill-biased technical change (Galor and Moav; 2000, Acemoglu, 1998, 2002; Acemoglu and Restrepo, 2016). While recent and valuable contributions in this literature indicate that the abundance of low-skilled migrants induces a delay in the adoption of machinery and innovation (Lewis, 2011; Clemens et al., 2018), we highlight two important channels previously overlooked by this literature. First, we document that immigration responds endogenously to the adoption of technology on top of supply-driven immigrant inflows. Second, we highlight the role immigration plays in shaping occupational choices, skill upgrading, and native welfare, when both technology adoption and immigration are present.

\section{Empirical Facts}

In this section we present some simple empirical facts and regression results that provide strong support for two regularities. First, labor markets (commuting zones) with intense computerization attracted a significantly larger number of foreign-born workers as a share of overall employment. This tendency already has been partly documented, as it was known that highly productive urban economies attracted highly educated workers in the 1980-2010 period (e.g. Diamond, 2016). Here we show specifically that areas with strong computerintensive productivity change attracted both high and low educated foreign-born workers.

\footnotetext{
${ }^{6}$ Llull (2018) adds the education and labor participation adjustment margins to the more traditional literature on the effects of immigration on natives wages and employment using a more structural approach. With respect to this paper, we focus on technological advancements, its interplay with immigration and their effects on job and wage polarization.
} 
The complementarity of computerization and analytical jobs cannot explain the inflow of less skilled immigrants, but another feature of that group can. Specifically, unskilled immigrants were significantly more specialized in manual occupations in the service sector, relative to unskilled natives who tended to specialize in routine jobs. Moreover, manual tasks supplied by immigrants increased significantly more during this time. Hence, computer-intensive productivity growth that substituted routine tasks and increased demand for manual service tasks attracted disproportionately lower skilled immigrants.

Second, we show the "polarizing" impacts of computerization on native and foreign born employment and wages. This analysis suggests that the rise in service occupations, which are intensive in manual tasks, due to the rise of computerization is largely concentrated among the foreign born population. Let us also notice here that the literature that analyzes the labor market impact of computerization finds an effect on reallocation of jobs and on relative wages but not on unemployment or on net employment (see for instance Autor, Dorn and Hanson, 2015). *** A recent contribution by Autor and Salomons (2018) disentangles the channels of labor reallocation due to technological advancements and concludes that in the aggregate technology does not lead to higher non-employment. ${ }^{7} * * *$ Similarly the literature $^{*}$ looking at effects of immigrants (e.g. Peri and Sparber, 2009, Basso and Peri, 2015) does not identify an impact of immigrant inflow on employment or unemployment of natives. In the current analysis, we focus on the long-run effects of these two mechanisms together, and we also emphasize the effect on reallocation of labor and relative shares assuming non significant impacts on unemployment rate and net employment.

\subsection{Computerization: Measurement}

We first construct a measure of "computer adoption" at the local economy level (commuting zones) between 1980 and 2010. We combine information on PC use at work at the industry level in the spirit of Autor et al. (2003) as measured by the 2003 Current Population Survey. Then, we impute this measure at the local level exploiting the industrial structure of each commuting zone as of 1980.

In details, we exploit the information contained in the 2003 CPS microdata, as available

\footnotetext{
${ }^{7}$ See also the robustness check in Appendix section A1 that corroborates these findings.
} 
on IPUMS (Ruggles et al., 2015), to construct the nationwide industry-level share of PC use at work as of mid-2000s. Given that in the early 1980s the use of computers at work was extremely limited, we consider the mid-2000s share as the cumulated adoption of PC at work, a measure of computerization of each industry in the three decades from 1980 to 2010. ${ }^{8}$ Then from the Census microdata of 1980 (Ruggles et al., 2015), we construct the industry composition of each commuting zone. Our sample is comprised of foreign and US born individuals of working age (between 18 and 65 years old), not residing in group quarters and not enrolled in school. ${ }^{9}$ We consider as employed all individuals with a positive number of weeks worked during the previous year. This is the sample definition we also use in the rest of the analyses in the paper aggregating population and employment at the commuting zone level, which approximates a local labor market and encompasses the entire 48 adjoining US states.

In equation terms, our CZ-level PC use measure is constructed as follows:

$$
\mathrm{PC} \text { use }_{c, t}=\sum_{j} \omega_{j, c, 1980} * \Delta \frac{\mathrm{PC} \text { at } \text { work }_{j, U S, t}}{e m p l_{j, U S, 1980}}
$$

where, for each CZ c, survey year $t$ (1980 and 2010), and industry $j$ :

$$
\text { - } \Delta \frac{\mathrm{PC} \text { at work }_{j, U S, t}}{e m p l_{j, U S, 1980}}=\frac{\mathrm{PC} \text { at work }}{e m p l_{j, U S, 2005}}-\underbrace{\frac{\mathrm{PC} \text { at } \operatorname{work}_{j, U S, 1980}}{e m p l_{j, U S, 1980}}}_{\sim 0}
$$

- $\Delta \frac{\mathrm{PC}_{\text {at }} \text { work }_{j, U S, t}}{e m p l_{j, U S, 1980}} \sim \frac{{\mathrm{PC} \text { at } \text { work }_{j, U S, 2005}}_{e m p l}}{e m, U S, 1980}$

- $\omega_{j, c, 1980}=\frac{e m p l_{j, c, 1980}}{\sum_{j} e m p l j, c, 1980}$

Our variable differs from a standard Bartik (1991) instrument for labor demand as we use as time shifter a proxy for the growth of PC adoption in a given industry (rather than of wages or employment growth) in order to capture the degree of routine-substituting technological change, or computerization. As long as our measure of PC use and a proxy for labor demand based on wage growth are not perfectly collinear, we can additionally control for changes in labor productivity. Thus, we will include in all main specifications a time-varying

\footnotetext{
${ }^{8}$ As of 1984, the percentage of households with a personal computer at home was around 8 percent, according to the Census.

${ }^{9}$ We define foreign born as those who are born outside the United States and are not US citizens at birth.
} 
variable constructed as traditional Bartik-style proxy that interacts CZs industry shares and nationwide industry wage growth and controls for generic labor demand shocks.

The constructed measure of PC use is strongly correlated with the routine-intensity measure used by Autor and Dorn (2013). This is shown in Figure 1, which represents a scatterplot across commuting zones of the 1980 routine share of local jobs as defined by Autor and Dorn (horizontal axis) and the PC use measure (vertical axis). The positive and strong correlation (the unweighted regression coefficient is 36.1 and it is statistically significant at .01 percent) indicates that PC use is correlated with routine-intensity in a commuting zone, and hence with the routine-substituting hypothesis put forward by Autor et al. (2003) and Autor and Dorn (2013). Our measure has the advantage of genuinely capturing sector-driven growth through the adoption of a disruptive automating technology, rather than constructing a task-based measure.

A further validation of our strategy is provided in Figure 2, which shows the correlation between the PC use proxy (on the vertical axis) and the self-reported use of computers by firms of Beaudry et al. (2010). ${ }^{10}$ Once again, the correlation is positive and statistically significant (the unweighted regression coefficient is 4.7 and it is statistically significant at .01 percent). Table 1 reports a whole set of correlations that corroborates the validity of our results. Moving from column 1 to column 4, we report unweighted correlations, correlations weighted by the 1980 size of the CZs, within state correlations and correlations in which we also control for a proxy for labor productivity. All the estimated $\beta$ s are positive and strongly statistically significant, indicating that our proxy captures a structural transformation of labor demand related to the adoption of a routine-substituting technology.

\subsection{Computerization and migration}

In order to use local area variation to test the correlation between computerization and migration, we define the immigration inflow at the commuting zone level as the change in the local population over a 30-year period divided by the beginning of decade CZ population, $\Delta P_{o p} p_{c, t}=\frac{P_{o p_{c, t}-P o p_{c, t-30}}}{P o p_{c, t-30}}$. In order to test whether mobility as a function of PC adoption

\footnotetext{
${ }^{10}$ The measure is standardized and available for $660 \mathrm{CZs}$ as reported by Autor and Dorn (2013) in their publicly available data.
} 
differs across demographic group, we breakdown total CZ population in four groups: low and high-skill natives, and low and high-skill foreign born. In particular, we define low-skill as those with high school degree or less and high-skill those with some college or more, and natives and foreign-born based on their nativity status. The change in population, in particular when looking at foreign born migrants, is relative to the whole CZ population at the beginning of the decade to avoid spurious correlations that may arise from endogenous native mobility responses to local labor demand shocks (Basso and Peri, 2015; Card and Peri, 2016).

Specifically we run the following regressions:

$$
\begin{gathered}
\frac{U S b_{c, t}^{h}-U S b_{c, t-30}^{h}}{P o p_{c, t-30}^{h}}=\beta \mathrm{PC} \text { use }_{c, t}+\gamma \text { Labor Productivity }_{c, t}+\phi_{s}^{h}+\Delta \varepsilon_{c, t}^{h}, \\
\frac{F b_{c, t}^{h}-F b_{c, t-30}^{h}}{P o p_{c, t-30}^{h}}=\beta \mathrm{PC} \text { use }_{c, t}+\gamma \text { Labor Productivity } \\
c, t \\
+\phi_{s}^{h}+\Delta \varepsilon_{c, t}^{h},
\end{gathered}
$$

where $h$ stands for either low-skilled or high-skilled and PC use ${ }_{c, t}$ is the measure of computer adoption defined above. State fixed effects $\left(\phi_{s}\right)$ are included in order to control for timevarying demand factors specific to states, and $\varepsilon_{c, t}^{h}$ are zero-mean random errors that we cluster at the state level. The variable Labor Productivity is a proxy for long-run changes in labor productivity as described in the previous paragraph.

The estimates of the $\beta$ coefficients from equation (2) and (3) are shown in Table 2. Some interesting results emerge. First, both high and low-skill population changes are positively correlated with the proxy for PC adoption, but the coefficients are statistically significant only for three groups: low-skilled foreign born and both high-skilled natives and foreign born. Second, and most interestingly, low skilled immigrants increase at twice the rate low skilled natives increase: a one percentage point increase of the $\mathrm{PC}$ adoption proxy is associated with a 0.22 percentage points increase in the low skilled native commuting zone share, and with a 0.55 increase of the low skilled immigrants, only the latter being statistically significant. While previous papers had focused on the inflow of high skilled into high productivity cities (e.g., Moretti, 2013; Diamond, 2016), and the contribution to non-routine-biased technical 
change from foreign-born scientists and professionals (Jaimovich and Siu, 2018), our paper emphasizes that inflows of low skilled immigrants are significantly associated with computerization at the local level. We also check that our measure is not correlated to pre-1980 immigration, ruling out spurious correlations due to long-run unobserved and persistent trends. In Table 3, we show that our proxy for PC use does not systematically predict the 1950-1980 immigration inflows, a period in which the adoption of PC was extremely limited and routine-biased technical change did not drive the changes in labor market structure (Autor and Dorn, 2013). The regression confirms that 1980-2010 PC use at work is not correlated systematically with other unobserved and persistent factors affecting long term population movements. ${ }^{11}$

Finally, Table 4 reports the estimates of equations (2) and (3) where we regress native and foreign born employment rather than population growth. The results confirm that highskill employment grows more in areas with more PC adoption regardless of nativity, while are a bit noisy when looking at foreign-born low-skill employment albeit still positive and larger in magnitude than the point estimate of low-skilled native employment. ${ }^{12}$

\subsection{Computerization and polarization}

We now test whether our computer adoption measure is associated with changes in the indexes of analytical, routine and manual task specialization, and in employment shares of occupations that mainly provide any of these three tasks. To do this we construct two different measures capturing these three types of task specialization. The first builds upon previous work that analyzes migration and occupational choices within the task framework (Peri and Sparber, 2009). We construct a set of 330 occupations that are consistently defined across Censuses. Then, we exploit the information contained in the Dictionary of Occupational Titles (DOT) database (US DOL, 1977), which indicates the task performed in

\footnotetext{
${ }^{11}$ The only exception being the coefficient on high-skill natives that is positive, but implausibly large, suggesting that in the pre-period our proxy for PC adoption may be capturing other determinants of migration.

${ }^{12}$ Appendix Table A3 reports a robustness exercise in which we show that non-employment has not significantly changed in areas with more PC adoption. In particular, we detect no statistically significant employment effects from $\mathrm{PC}$ use for low-skilled natives, while we estimate sizable employment effects from PC use for high-skilled natives. This result is consistent with evidence in Autor et al. (2015) and Autor and Salomon (2018).
} 
each occupation as of 1977. We focus on the indexes of analytical, routine and manual tasks, as previously done by Autor et al. (2003) and Autor and Dorn (2013). Each of the three indexes represents the percentile of each occupation in the distribution of occupations ranked by task in 1980. Each worker, therefore, has an index that reflects her/his specialization in analytical, routine and manual tasks, which can then be aggregated by Census year and local labor market. ${ }^{13}$ These indexes of task specialization are exclusively based on the occupational task intensity relative to all other occupations in the economy, thus they purely reflect characteristics of the occupations as classified at the beginning of our sample period. In the rest of the analysis we normalize these indexes, dividing by the total supply of tasks in each Census year and local labor market to better capture the changes in the polarization of foreign-born and natives' specialization.

Acemoglu and Autor (2011) suggest it may be preferable to work with occupations directly because task indexes such as those constructed above may not accurately reflect the actual task structure (Acemoglu and Autor, 2011, page 1078). Thus, we also look directly at occupational employment shares. Following Autor and Dorn (2013) we categorize occupations into three distinct groups by simply aggregating managerial, professional and technical occupations, routine occupations (mainly clerical, sales, precision production and machine operators) and non-managerial/non-routine occupation (personal services, construction, mechanics and agricultural workers). This partitioning is obtained simply by following the classification of Autor and Dorn (2013), and identifying the occupations that entail the largest use of analytical, routine or manual tasks, respectively. The task-intensity of each group of occupations (managerial, routine and non-managerial/non-routine) is reported in Table 5. It shows the high analytical content of managerial occupations, the high routine content of routine occupations, and the high manual content of services/construction/transportation occupations. The correspondence is of course not exact, but it provides an alternate and simple way of thinking about what analytical and routine jobs actually are. The downside of this approach is that, in an effort to identify occupations that are more plausibly affected by "routine-substituting" technological change, we may select occupations only based on

\footnotetext{
${ }^{13}$ Table A1 in the appendix lists the ten occupations with the highest value of each task intensity index. The details of the classification procedure are described in the Data Appendix.
} 
anecdotal evidence. Reassuringly, the two methods give very consistent results.

Figure 3 uses the task specialization indexes, our first measure described above, for four groups of workers - low skilled natives, low skilled immigrants, high skilled natives and high skilled immigrants - to establish an important fact. It shows the changes in the supply of each type of task in the US labor market by the four groups mentioned above, after standardizing their initial value to 1 in 1980. Panel (a) shows the changes for low skilled immigrants, Panel (b) for high skilled immigrants, Panel (c) for low skilled natives and Panel (d) for high skilled natives. One difference between immigrants and natives, especially in the low skilled group, is evident from panels (a) and (c). Low skilled immigrants are specialized significantly more in manual tasks relative to natives, and significantly less in analytical ones. Already apparent in 1980, this difference became even larger during the 1980-2010 period when the index of manual tasks increased significantly more for low skilled immigrants than for low skilled natives. Even high skilled immigrants increased their manual specialization more than high skilled natives. On the other hand, immigrant specialization in routine tasks was relatively similar to the natives' one as of 1980, and declined at roughly the same rate. Table 6 summarizes the average intensity of each type of task index for natives and foreign born in 1980 and 2010 as well as the change over the period (Table 7 does the same for the occupation groups). This table shows even more clearly that in the aggregate the specialization in manual tasks for natives has declined since 1980, while the foreign born increased their specialization in such tasks.

Hence, as a group, immigrants' specialization in manual tasks increased relative to routine tasks (and to analytical tasks) especially among less educated workers. This is an important feature differentiating foreign and native low skilled workers and it will play an important role in our story. Related to the significant "manualization" of immigrant jobs relative to natives over the period 1980-2010, there is another interesting stylized fact not very well known or even discussed in the "polarization" literature. As firstly noted by Mandelman and Zlate (2014), and demonstrated in Figure 4, we see that labor polarization at the low end of the skill spectrum is a phenomenon almost exclusively related to immigrant employment. ${ }^{14}$

\footnotetext{
${ }^{14}$ Mandelman and Zlate (2014) develop a three-country dynamic stochastic general equilibrium model in which polarization is attenuated by low-skilled undocumented immigrants. We see this valuable work as complementary to ours as they reach similar conclusions despite substantial differences: first, their driver for
} 
The figure shows the percent growth in employment, ranking 330 occupations by their wage percentile in 1980, separately for foreign-born (blue line) and natives (red line). Occupations at the very low end of the 1980 wage percentile distribution (below the 20th percentile), experienced large employment growth over this period (15-20\%), but this phenomenon was essentially limited to foreign-born. Native employment growth below the 20th percentile was actually negative. To the contrary, occupations at the high end of the 1980 wage percentile distribution (above the 60-70th percentile), which also experienced significant employment growth $(+15 \%)$ mainly added native jobs as the employment growth of immigrants in this range was much smaller. Finally intermediate occupations (between the 30th and the 60th percentile) which did not grow much in terms of employment for either group, still show higher employment growth for natives relative to immigrants. Figure 5 reports a similar fact, but here we divide each bin by total employment (native and foreign born), thus highlighting the contributions of each group. The share of foreign born employment increased along the distribution in an homogeneous way, but at the low end where the growth reached up to 25 percent. Figures 4 and 5 show, in essence, that the polarization of employment at the low end of the wage distribution was due to immigrant jobs and at the high end to native jobs. And natives did better than immigrants in terms of employment growth in the intermediate wage range. If low-paying manual tasks complement routine-intensive intermediate-tasks, immigrant labor supply responding to computer adoption may have attenuated the decline in demand of routine tasks and in routine-employment of natives.

We further test this evidence in a regression framework exploiting CZ-level variation in $\mathrm{PC}$ adoption and changes in the occupational structure and task specialization observed at the local level. We estimate the coefficient $\beta$ in the following regression:

$$
\Delta y_{c, t}^{k}=y_{c, t}^{k}-y_{c, t-30}^{k}=\beta \mathrm{PC} \text { use }_{c, t}+\gamma \text { Labor Productivity }_{c, t}+\phi_{s}^{k}+\Delta \varepsilon_{c, t}^{k},
$$

where $y_{c, t}^{k}$ represents the native specialization intensity for each task $k$ (representing alternatively analytical-, routine- and manual-intensive) for commuting zone $c$ and year $t$, and

polarization is off-shoring and not automation contrary to the empirical evidence (Autor, Levy and Murnane, 2003; Goos, Manning and Salomons, 2014); second, they model immigration as high-school dropout illegal immigration inflows from Mexico only. 
the operator $\Delta$ captures the 30-year difference. We run the regression in differences, thus removing time-invariant unobservable local labor market characteristics. We further control for state fixed effects $\left(\phi_{s}^{k}\right)$, which capture region specific shocks in the three decades, and we control for local changes in labor productivity over time. We also run a similar specification, where on the left hand side we have the employment shares of three occupation groups: managerial/professional, clerical/sales/operators and services/construction/transportation.

Table 8, Panel A reports the estimates of coefficient $\beta$ from equation (4) above for natives, and Panel B for foreign born using the native employment of analytical, routine and manual indexes, respectively, as dependent variables. Table 9 does the same for the occupational share of managerial/ professional, clerical/ sales/ operators and services/ construction/ transportation as dependent variables. The results are consistent across the two occupational partitions and suggest a significant role of PC adoption in producing task-driven labor demand changes. A one percentage point increase in the use of computers at work is positively associated with the share of analytical-intensive and manual-intensive employment, and it is negatively associated with the share of routine-intensive employment. The "polarization" effects are even stronger when we use managerial (as analytical intensive) and clerical (as routine intensive) occupations. Managerial and professional occupations, whose task specialization is prevalently analytical, increased their share by 0.56 percentage points between 1980 and 2010 among natives and 0.60 among foreign born for a one percentage increase in PC use at work. In the same period, the employment shares of clerical and machine operator (prevalently routine) declined by 0.65 percentage points among natives and by 1.04 among foreign born; non-managerial/non-routine (prevalently manual) occupations increased among natives, but not in a statistically significant way, but increased among foreign born by 0.44 percentage point for each one percentage point increase in PC use at work. These results, although simple associations, indicate that the increase in manual task specialization and service occupations is larger for foreign born than for natives. This confirms the intuition from figures 4 and 5: job market polarization among natives is less pronounced at the low-end and the aggregate increase of service jobs is largely due to a combination of demand for services and supply of foreign born workers.

If employment does not fully respond to the relative demand changes described above, 
wages for routine-intensive jobs should decline and those for manual-intensive jobs should increase in areas of strong computer-use growth. However, exposure to larger immigrant supply should attenuate these wage effects on natives, especially among those who work in the service sector.

In Table 10 we test whether the changes in labor market polarization combines elements of demand and supply shocks. We study the average change of occupational wages between 1980 and 2010 separately for natives and foreign born. Coherent with a demand shock, we observe a rise of managerial/professional wages and a drop of clerical/sales/operators wages as computer use substitutes for routine tasks and complements high-skilled analytical labor. Such changes are similar in magnitude for natives and foreign born. Differently from what documented in the existing literature we do not observe a rise in service workers wages: for both groups the change is very small and statistically not significant. Such null results suggests that a labor supply shock may have accompanied the increase in demand for manual services already documented in the previous literature (Autor and Dorn, 2013; Mazzolari and Ragusa, 2013).

Summarizing the empirical findings of this section, we can say the following. (i) We constructed a proxy for local computer adoption at work for the period 1980-2010, which is negatively correlated with routine-task demand and positively correlated with manual-task

demand. (ii) This PC use measure, which we take as a measure of local computerization of production, was strongly associated with immigration of both high and low skilled foreign workers, and of high-skill natives. (iii) Foreign born are largely responsible for the growth of manual-intensive service employment, thus contributing to the low-end employment polarization.

\section{Model}

To rationalize and make sense of these results, we now consider a model in which computercapital deepening, as a result of lowering its price, drives changes in labor productivities, wages and immigration. The value of developing a formal theory involve a number of factors. First, the model can help implicitly test to see if our empirical findings can be reproduced 
under plausible scenarios. Second, by matching certain stylized facts established by the data, the model can shed light on other factors, such as the effects migrants can have on subsequent computerization. Finally, the model can help us see the welfare implications arising from endogenous migration flows.

A simplified version of this model is discussed in the Appendix section A4 - in this and subsequent sections we lay out the full theory. We begin with a framework similar to Autor and Dorn (2013), and we extend it to include endogenous changes to the supply of labor through immigration, as the inflow of immigrants respond to domestic wage changes. In the model we mainly focus on unskilled immigration. This group has been a very important portion of immigration in the 30 years since 1980, and as we show in the previous section, it seems crucial to the mechanism of comparative advantages and specialization in response to technological change. This will be the focus of our analysis. We include the possibility of skilled immigration in subsequent discussion, although we do not focus on immigrants' ability to innovate and specialize in technological jobs, as some other recent studies have done (e.g. Bound et al., 2018, and Jaimovich and Siu, 2018).

The economy consists of two sectors which produce goods, denoted as $g$, and services, denoted as $s$. They are imperfectly substitutable in the utility of the representative agent in the economy. For simplicity we solve the social planner's problem (which produces the same result as general equilibrium) and hence we maximize:

$$
\left(\rho C_{s}^{\frac{\sigma-1}{\sigma}}+(1-\rho) C_{g}^{\frac{\sigma-1}{\sigma}}\right)^{\frac{\sigma}{\sigma-1}}
$$

subject to the constraints discussed below. Here $C_{s}$ and $C_{g}$ are per capita consumption of services and goods, respectively, and $\rho$ is the relative weight placed on services in the representative agent utility function. The parameter $\sigma \leq 1$ determines the elasticity of substitution between goods and services. We will assume throughout that $\sigma>0$, so that goods and services grossly complement each other in utility. ${ }^{15}$

There are three basic factors of production - "computer capital" $(K)$ which we sometimes call "computers" for simplicity, skilled or analytical labor $\left(L_{a}\right)$, and unskilled labor

\footnotetext{
${ }^{15}$ This is an important assumption, adopted also in Autor and Dorn (2013), justified by the fact that goods and services are quite differentiated from each other.
} 
$(U)$. The difference between skilled and unskilled labor is that an individual has to pay an education (training) cost to be skilled so that she can supply her labor as analytical. As the cost of training is paid every period and we are implicitly assuming that skills are fully used in the production of a final good, one can think of a model as representing infinitely lived households, with successive generations of people with independent skills and education. This is a simple way of modeling costly human capital acquisition. Computer capital and skilled labor can only work in goods production (manufacturing). Unskilled labor can be employed in either manufacturing or services. However unskilled workers are heterogeneous and they supply different "ability" levels in performing the "routine" tasks that are needed in manufacturing, and we denote their total supply of these tasks as $L_{r}$. They can also supply non-routine (service) tasks in the service production (whose supply we denote as $L_{s}$ ). Individuals have different relative abilities in routine tasks and we will discuss this later. The total effective supply of unskilled workers $U$, therefore, is split between routine and service supply so that $U=L_{r}+L_{s}$.

Consumption of services and goods are subject to the following resource constraints:

$$
\begin{gathered}
C_{s}=Y_{s}, \\
C_{g}=Y_{g}-p_{k} K-p_{a} L_{a},
\end{gathered}
$$

where $Y_{s}$ is total production of services, $Y_{g}$ is total production of goods, $p_{k}$ is the price of computer capital, and $p_{a}$ is the price of analytical skills. We have standardized the price of the manufacturing good to one. Equation (7) shows that in each period resources, in the form of goods, must be paid to obtain physical and human capital in this economy. Essentially part of total income in the economy goes each period to investment in human capital and training to upgrade workers from unskilled to skilled. We will also assume that computer capital depreciates completely each period, and so will need to be replenished each period. The price (of physical and human capital) are exogenously given. These prices may be thought of as the technological efficiency of converting goods into physical and human capital units. Hence, in a broad sense, they represent the cost of computer capital and 
schooling. The exogenous decline in the cost of computer capital will be the exogenous technological force at the basis of all the changes that we will analyze. Unskilled service workers produce services with a linear technology and have all the same productivity in those tasks, so that with a standardization of units we can write the production function in the service sector as: $Y_{s}=L_{s}$. Goods, instead, are produced according to the following function:

$$
Y_{g}=\left[\left(\alpha_{a} L_{a}\right)^{\beta}+X^{\beta}\right]^{1 / \beta}
$$

where

$$
X=\left[L_{r}^{\gamma}+K^{\gamma}\right]^{1 / \gamma}
$$

Here $X$ is a CES aggregator, composed of routine labor services $L_{r}$ and computer capital. The elasticity of substitution between analytical labor services and the term $X$ is $1 /(1-\beta)$, $\beta<1$. The elasticity of substitution between routine labor and capital within the composite $X$ is $1 /(1-\gamma), \gamma<1$. We make the key assumptions that routine labor and capital are grossly substitutable, which implies $0>\gamma>1$. This property is consistent with the fact that computer capital, in the form of increasingly efficient computers, has substituted many routine tasks such as data entry, typing, classifying, book keeping and other similar tasks. We also assume that analytical labor and the capital aggregate are grossly complementary, which implies $\beta<0$, reflecting the higher productivity of analytical and creative abilities when the supply of computer capital increased. We will also assume that $\alpha_{a}>1$ to reflect the idea that analytical labor has greater productivity potential than routine labor. All this is already contained in Autor and Dorn (2013).

\section{Labor and Skill Amounts}

All workers are paid their respective marginal products. The total amount of labor in the economy will be made up of a unitary mass of native workers plus a mass of migrants, mig, that flows into the economy in response to labor productivity and wage growth (more on this below). Native workers are indexed by their ability which equals $\eta_{i}$ for worker $i$. We consider this as an endowment distributed in the population as described below. $\eta_{i}$ takes on 
positive values ranging from 0 to $\infty$. This can be thought, more precisely, as the ability to perform routine or analytical tasks relative to the ability to perform manual/service tasks which is common to all workers and standardized to one.

We also assume that the process of education/training for worker $i$ is equivalent to an "upgrade" of her endowment-ability so that $i$ can use her abilities as an analytical worker. She must however expend a lump sum amount of $p_{a}$ (in units of goods) in training in order to do this. This price represents a cost of "education" (or training) and our assumptions capture the idea that education will proportionally increase the innate productivity of a worker. Let us emphasize that this margin, absent in Autor and Dorn (2013), provides workers access to a different labor market, specifically that for workers in the manufacturing sector who supply analytical services. Alternatively, if they remain unskilled, native workers may choose whether to work in service production, or use their routine ability in manufacturing production.

As a consequence of our assumptions there are two relevant ability thresholds for native workers. Specifically, we call $\eta^{*}$ the ability level at which a worker would be indifferent between being either a low-skilled manual/service worker or a low-skilled routine worker. For all endowments of $\eta<\eta^{*}$ workers will prefer to supply manual services to the service sector, as this would provide them a higher compensation. For $\eta>\eta^{*}$ workers will supply routine services to the goods-producing sector. Let $\hat{\eta}$ instead be the threshold at which a worker would be indifferent between being either a low-skilled routine worker or paying the education cost to become a high-skilled analytical worker. Thus the two thresholds can be characterized by the following conditions:

$$
\begin{gathered}
w_{r} \eta^{*}=w_{s}, \\
w_{a} \hat{\eta}-p_{a}=w_{r} \hat{\eta},
\end{gathered}
$$

where $w_{r}, w_{s}$ and $w_{a}$ are the market wages paid to routine, service and analytical labor respectively, and $p_{a}$ is the training cost to be able to supply analytical labor.

Finally, we assume that native workers' ability is distributed as a negative exponential 
over the interval $[0, \infty]$. The density is given by $f(\eta)=\lambda e^{-\lambda \eta}$, where $\lambda>0$, and the total mass of native labor force is standardized to 1.

A key novelty of our model is to introduce an immigration response to wages and to allow immigrants to supply abilities that are different from those of natives. We model the supply and the abilities of immigrants in a very simple way. We focus on a case in which immigrants are all unskilled, and we standardize their ability endowment to be equal among them and low enough that they will always supply manual tasks with a productivity of one (we introduce the possibility of skilled migrants in a later section). This assumption captures the fact that unskilled immigrants are likely to have a higher relative productivity in manual service tasks which are easily transferred across countries (cooking, cleaning, building, gardening) rather than in routine tasks that are more specifically related to manufacturing and working with machines, and more related to communication-oriented tasks. We assume that unskilled migration is negatively related to a cost of migration $p_{s}^{m}$, and positively related to service wages $w_{s}$ in the economy, as unskilled immigrants can only work in that sector. Note that $p_{s}^{m}$ can include the wages earned by the migrant in their country of origin - in this case it can be interpreted as an opportunity cost of migrating. Such costs are not a function of changes in the host economy, and so we treat $p_{s}^{m}$ as exogenous. We assume a simple functional form that implies a log linear supply response to wages, which is qualitatively in line with a simple model of immigration choice, such as Grogger and Hanson (2011). The reduced form immigration equation is as follows:

$$
m i g= \begin{cases}\left(1+w_{s}\right)^{\epsilon}-\left(1+p_{m}^{s}\right), & \text { if }\left(1+w_{s}\right)^{\epsilon}-1>p_{m}^{s} \\ 0, & \text { otherwise }\end{cases}
$$

where mig is the mass of unskilled migrants and $\epsilon,(\epsilon>0)$ governs the extent to which unskilled migrants respond to potential income in the host economy. A low value of $\epsilon$ can mean that service wages do not translate into much utility for immigrants, while a high value of $\epsilon$ suggests that wage earnings translate strongly into utility and this would then have a strong effect on their labor supply. This parameter captures the sensitivity of immigration flows to changes in unskilled wage in the destination country, an elasticity that several 
papers estimate to be positive and significant (e.g., Mayda, 2010). It will be determined by a combination of the distribution of unobserved skills of immigrants, and by immigration policies.

Under the assumptions described above the total effective supply (i.e. weighted for units of ability/efficiency) of routine and analytical labor can be written as follows:

$$
\begin{aligned}
L_{r} & =\int_{\eta^{*}}^{\hat{\eta}} \eta e^{-\eta} d \eta, \\
L_{a} & =\int_{\hat{\eta}}^{\infty} \eta e^{-\eta} d \eta .
\end{aligned}
$$

The total mass of unskilled service workers on the other hand is given by

$$
L_{s}=m i g+\int_{0}^{\eta^{*}} e^{-\eta} d \eta
$$

where mig is the endogenously determined total mass of unskilled immigrants in the economy. All immigrants here are assumed to be unskilled, and they have an average ability equal to one, so that they only supply service labor in an amount effectively equal to their mass. There will be $1+m i g$ total individuals in the economy between native and foreign-born.

The distribution of potential analytical and routine skills remains fixed in the economy. However, changes in technology will have wage effects. These will then change $\eta^{*}, \hat{\eta}$ and mig, and these will cause adjustments in equilibrium labor amounts.

\subsection{Equilibrium Conditions}

What characterizes an equilibrium in this simple economy? For exogenously given $p_{a}, p_{k}$, $p_{m}^{s}$ and $\epsilon$, we must have the demands of each factor $\left(L_{a}, L_{r}, L_{s}\right.$ and $\left.K\right)$ equal the respective supply of each. Demand is determined by what each factor provides marginally. These are given below:

$$
\frac{\partial Y_{g}}{\partial K}=\frac{\partial Y_{g}}{\partial X} \frac{\partial X}{\partial K}=p_{k}
$$




$$
\begin{gathered}
\frac{\partial Y_{g}}{\partial L_{r}}=\frac{\partial Y_{g}}{\partial X} \frac{\partial X}{\partial L_{r}}=w_{r}, \\
\frac{\partial Y_{g}}{\partial L_{a}}=w_{a} .
\end{gathered}
$$

Furthermore, utility maximization yields us

$$
\left(\frac{\rho}{1-\rho}\right)\left(\frac{C_{s}}{C_{g}}\right)^{-\frac{1}{\sigma}}=\left(\frac{\rho}{1-\rho}\right)\left(\frac{L_{s}}{Y_{g}-p_{k} K-p_{a} L_{a}}\right)^{-\frac{1}{\sigma}}=w_{s} .
$$

The supplies of each labor type will be determined by the threshold levels of human capital - the amount endowed to the person indifferent between routine and service work, and that endowned to the person indifferent between routine and analytical work. These are given by

$$
\begin{gathered}
\eta^{*}=\frac{w_{s}}{w_{r}}, \\
\hat{\eta}=\frac{p_{a}}{w_{a}-w_{r}} .
\end{gathered}
$$

Finally, solving (13), (14) and (15) allows us to solve for equilibrium amounts of total skilled and unskilled employment:

$$
\begin{gathered}
L_{r}\left(\eta^{*}+1\right) e^{-\eta^{*}}-(\hat{\eta}+1) e^{-\hat{\eta}}, \\
L_{a}=(\hat{\eta}+1) e^{-\hat{\eta}}, \\
L_{s}=1+m i g-e^{-\eta^{*}} .
\end{gathered}
$$

A formal equilibrium is thus given by solving the system of equations (12), (16), (17), (18), (19), (20), (21), (22), (23), and (24) for values of mig, $K, w_{r}, w_{a}, w_{s}, \eta^{*}, \hat{\eta}, L_{r}, L_{a}$, and $L_{s}$. 
What are the channels for immigration to affect the equilibrium wages and employment levels of natives? As mig rises we might expect unskilled wages $w_{s}$ to fall as immigrants increase the supply of unskilled service workers (19). This, however, also lowers $\eta^{*}$, the routine-skill/service threshold for natives (20), which then generates a larger number of native workers choosing routine tasks in manufacturing increasing the routine supply in the economy $(22)$.

Note that higher levels of services should also raise the relative value of goods in the economy. Such an effect can be considered as the "demand effect" of immigrants, who produce more services but they also contribute to the demand of complementary goods. And this effect attracts additional capital (as the price of capital is exogenously determined), which should then raise the value of analytical skills, which complements this capital in production (18), to the advantage of native workers. Note that this also implies that the threshold level of analytical skills in the economy should then fall (21), generating more analytical skills in the economy as well (23).

Of course, migration itself is endogenous in our model. To see if the results suggested above hold when unskilled migration is treated endogenously, we next turn to simulation.

\subsection{Parameter Values and Model Simulation}

In quantifying parameters for our model simulations, we characterize two types — "calibrated" values and "free" values. Parameters and baseline values are summarized in Table 11.

In this model we produce one type of exogenous shock to the economy — improvements in technology, represented by exogenous decreases in the price of capital, $p_{k}$, each time period. By so doing we can observe the impact of such changes on the flow of unskilled immigration, as well as the general equilibrium effects on native earnings and employment each time period.

Specifically, we simulate technological improvement by exogenously lowering the price of capital $p_{k}$ by 44 percent cumulatively. Using the extrapolated time series of Gordon (1990), Civale (2016) suggests such a decline in the relative price of investment goods when controlling for quality improvements from 1980-2010. We decrease $p_{k}$ from 4 to 2.6 over 
30 periods, roughly mimicking the IT-revolution in the US economy from $1980-2010 .{ }^{16}$ For unskilled migration, we set $p_{m}=\left(1+w_{s}\right)^{\epsilon}-1$ before any technological progress, so that there is zero migrants to start. For our chosen value of $\epsilon=0.2$, the cumulative drop in $p_{k}$, and our baseline parameter values, this produces a cumulative increase in unskilled labor due to migration.

For reasonable parameter values we first must ensure that $\beta<0$ ( $X$ and $L_{a}$ are grossly complementary), $\gamma>0$ ( $K$ and $L_{r}$ are grossly substitutable), $\sigma>0\left(C_{g}\right.$ and $C_{s}$ are grossly complementary in utility), and $\alpha_{a}>1$ (analytical labor is more productive than routine labor). Specific parameter values, along with justifications, are provided in Table 11. While elasticities can be reasonably calibrated from the literature, we have five "free" parameters with little to guide specific values: $\rho, p_{a}, \alpha$, initial $p_{k}$, and $\epsilon$. Picking these, we attempt to roughly match six conditions suggested by the data: initial labor shares that are close to 33 percent each, migration that rises to roughly 12 percent of the total native population, native routine employment falling by 12 percent, native analytical employment rising by 15 percent, and native service employment falling by 2 percent.

Our parameterization produces initial employment shares that can be seen in Figure 6. Specifically, initial shares of native employment are $N_{a}=0.20, N_{r}=0.33$, and $N_{s}=$ 0.47. Relative to initial shares suggested in table 2, we clearly have over-representation in the service sector and under-representation in analytical labor. Note that this biases our simulation towards finding negative welfare effects from unskilled migration. We describe this further below. A fuller description of parameterization is provided in the appendix.

We demonstrate both the directional changes in the model diagrammatically, and the we show quantitative magnitudes of changes in a table. Figures 6 to 10 demonstrate our baseline simulations through 30 periods (we discuss in the next section the case with both low and high skilled immigration). Table 12 displays the magnitudes of these changes. We demonstrate two basic cases. The first case is where $\epsilon=0$, illustrated with solid blue lines. In this case no immigration takes place as computerization occurs. The second case is our baseline where $\epsilon=0.2$, illustrated with red dashed lines. Here we observe moderate endogenous migration of a magnitude roughly consistent with the U.S.'s experience during

\footnotetext{
${ }^{16}$ In the simulation one period can correspond to one year.
} 
the three decades of 1980-2010 and computerization in the form of the decrease in price of capital.

From these simulation exercises we discover a number of interesting and informative findings which parallel our empirical findings. We summarize these below:

\section{1) Technological progress without migration generates labor market polar-} ization. That is technological progress produces an increase in employment for analytical and service workers while it produces a decline of employment for routine workers. We demonstrate this in Figure 6. Here we have $\epsilon=0$ so there is no migration, only exogenous decreases in capital prices. For native workers we observe a rise in analytical employment (by 32 percent), a fall in routine employment (by 24 percent), and a rise in manual service employment (by 3.6 percent). The latter two effects echo Autor and Dorn (2013).

The rise in analytical work here differs from Autor and Dorn, as they hold this employment level fixed. But this matches quite nicely our empirical findings demonstrated in Table 3, 4, 7 and 8. Using either measure of skill level (task-based or occupation-based), we observe computerization increase employment polarization for native workers.

The model also generates wage polarization. This is clear from Table 10 - wages for analytical labor rises relative to routine labor. And wages for service labor also rise relative to routine labor. We thus see that computer capital growth in the model produces the kind of polarization observed in the United States over the last few decades.

2) Technological progress attracts low-skilled migrants. This can be seen in Figure 7. As capital rises due to exogenous capital price declines, it lifts all wages, including those for manual-intensive service workers. This induces more foreign workers to pay the cost $p_{m}$ to enter the economy and earn $\left(1+w_{s}\right)^{\epsilon}-1$. For our illustrated baseline case, where $\epsilon=0.2$, we observe a technologically-induced immigrant inflow of roughly 12 percent of the total original workforce in the simulation. This finding matches the empirical results shown in Tables 2 and 4 - our empirical proxy of computer intensive productivity growth strongly correlates with low-skilled immigration. In fact compared with natives, the apparent attraction for high-skilled immigrants is relatively weak. This simulated labor flow also roughly mimics the rise in unskilled immigrants as share of the population observed in the United States for the past three decades (as described, for instance in Chapter 2-3 of Borjas, 2014). 
Thus, both empirically and theoretically, we show that low-skilled migration is a natural concomitant to economic growth. While this implication is straightforward, as long as immigrants respond to local wages, it has important implications for policy. Efforts to staunch the flow of migrants should be careful not to damage the fundamental source of this flow, or else risk productivity improvements more generally.

3) Immigration tends to reverse the de-routinization of native employment from technological change. In Figure 8, we observe that while technology hollows out routine employment among native workers (solid blue line), unskilled immigration tends to reverse this by putting downward pressure on $\eta^{*}$ (red dashed line). Specifically, in the simulation we see that computerization lowers native employment in routine occupations by roughly 24 percent over 30 periods. With our baseline case of moderate unskilled migration, computerization lowers native employment in these positions by only 13 percent, which closely matches what we observe empirically (see Table 6).

Again, our empirical findings lend support to this, both in terms of direction and magnitude. Given that immigration is itself responding to technological changes, greater openness to migrant inflows should be associated with less de-routinization, even as computerization rises.

4) Immigration raises the total earnings of routine native workers. The model demonstrates that immigration tends to increase capital even more given the price level of capital, raising overall production in manufacturing goods. This is an interesting and novel technological spillover from unskilled migration not observable by past partial equilibrium studies. One important implication of this is that any negative wage impact from unskilled migration are somewhat mitigated for all natives. Partial equilibrium analysis misses this ancillary effect from migration.

Specifically, because immigration produces an extra boost to capital, greater migration partially reverses the negative effect on total earnings for routine workers, and strengthens the positive effect on total earnings for analytical workers. And due to skill upgrade (see next point), any wage declines are more than offset by a larger share of routine workers due to migration. Earnings are raised by migrant flows for natives who employ their mid- or high-level skills. 
5) Immigration generates skill upgrading among native workers. With unskilled immigration, some erstwhile routine workers end up paying the fixed cost of schooling to upgrade to become analytical workers ( $\hat{\eta}$ falls). We can see this in Figure 9 - endogenous migration strengthens the skilling effects of technology for analytical work.

An important implication here is that unskilled immigration can lead natives to upgrade their education, and thus to become more productive in the workforce. This is an idea supported empirically by works such as Hunt (2016).

Overall, the model captures key elements of the empirical findings. Further, we present a simplified version of the model in the Appendix. Though the simpler model abstracts from the polarization aspects of our discussions here, it nonetheless echoes the basic findings we have presented, namely that unskilled migrants help natives upgrade their skills, and thus help bolster their earnings as a result.

Figure 10 provides some intuition regarding our overall results. Here we generate from the model demand and supply schedules for unskilled immigration into the economy. The horizontal axis shows immigrants as share of the population. Supply curves slope upward - these simply plot equation (12) in $m-w_{s}$ space. Demand curves slope downward these simply plot the utility-maximizing values of $w_{s}$ for given amounts of migrants (see equation 19) and their slope is determined by the fact that at higher costs of service labor people will demand less services. At point A there is no technological progress or any migration. Exogenous decreases in the price of capital, ceteris paribus, shifts the demand for migrants to Demand $_{2}$. This relates to point 2 - lower capital prices will naturally lead to greater unskilled immigration. However, there are also general equilibrium effects with such change. Growth in capital also leads to shifts in native employment, as natives upgrade their skills (points 3 and 5). This produces even greater productivity and capital growth in the economy, shifting demand to Demand $_{3}$ and fostering more unskilled immigration. Point B demonstrates the full results, where both wages and immigration robustly increase as a consequence of computerization.

\section{6) Unskilled immigration enhances aggregate welfare for natives.}

To demonstrate this point we can produce some indirect utility calculation derived from (5). For all natives working in manufacturing, utility is: 


$$
U t i l_{\text {manuf }}=\left(\frac{\rho^{1+\sigma} w_{s}^{-\sigma}+(1-\rho)^{1+\sigma}}{(1-\rho)^{\sigma}+\rho^{\sigma} w_{s}^{1-\sigma}}\right)\left(w_{r} L_{r}+w_{a} L_{a}\right)\left(N_{a}+N_{r}\right) .
$$

These individuals all unambiguously gain from unskilled migration - their earnings are higher, while the services they purchase are cheaper.

For natives remaining in services, utility is:

$$
U t i l_{\text {serv }}=\left(\frac{\rho^{1+\sigma} w_{s}^{-\sigma}+(1-\rho)^{1+\sigma}}{(1-\rho)^{\sigma}+\rho^{\sigma} w_{s}^{1-\sigma}}\right)\left(w_{s} L_{s, \text { nat }} L_{s, \text { nat }}\right)
$$

This group unambiguously loses, as the negative pecuniary externality produced by unskilled migrants more than offsets the cheaper services.

Figure 11 demonstrates changes in aggregate native welfare both with and without endogenous unskilled migration. In short aggregate welfare is greatly enhanced by this migration flow. Even though unskilled wage gains are entirely reversed by migration, the rise in capital and skill upgrade generate net welfare gains. Note that this is in spite of the fact that an unreaslitic share of natives remain in the service industry, at least compared to what the data suggests.

\subsection{Introducing Skilled Migrants}

We extend the basic analysis described above by including skilled migrants on top of unskilled (service) migrants. These two groups will be treated separately, and there are no immigrant routine workers. This captures the bi-modality of immigrant skills in the United States who, as shown for instance in Peri (2016), are particularly concentrated among less educated manual workers and highly educated professionals in cognitive-intensive jobs.

Each group must pay a fixed cost to enter the economy. Unskilled immigrants pay $p^{m}$, just as before. The immigrant analytical worker on the other hand earns $\eta_{m}\left[\left(1+w_{a}\right)^{\epsilon_{a}}-1\right]$ after paying a fixed $\operatorname{cost} p_{a}^{m}$, where $\eta_{m}$ is the analytical ability of the skilled immigrant, and $\epsilon_{a}$ governs the earnings of the skilled migrant. Notice that we allow skilled immigrants to have

different moving cost relative to unskilled, which is possibly due to their higher adaptability (if migrants are heterogeneous) or their higher options to remain in touch with the country 
of origin. This is a plausible and general assumption and adopted by Grogger and Hanson (2011) among others. Also note that earnings for the skilled migrant rises with $\epsilon_{a}$ for any $w_{a}>0-\operatorname{as} \epsilon_{a}$ approaches one, the skilled immigrant earnings approaches that of the skilled native. $\eta_{m}$ is distributed in the same way as for native workers. Let $\bar{\eta}$ be the amount of analytical ability held by the immigrant indifferent between staying home or paying the fixed cost to work as an analytical worker here. Then

$$
\bar{\eta}\left[\left(1+w_{a}\right)^{\epsilon_{a}}-1\right]=p_{m}^{a}
$$

Given this, we now have two sources of abstract labor:

$$
L_{a}=\int_{\hat{\eta}}^{\infty} \eta \lambda e^{-\lambda \eta} d \eta+\int_{\bar{\eta}}^{\infty} \eta \lambda e^{-\lambda \eta} d \eta .
$$

The first term is the total amount of analytical skill supplied by natives; the second term is the total amount of analytical skill supplied by migrants.

Again, we simulate technological improvement by exogenously lowering the price of capi-

tal, $p_{k}$, by the same amount as before, and look at cases with low and high levels of unskilled migrants. Now, however, we allow for endogenous inflows of skilled migrants as well. Technological changes will then change $\eta^{*}, \hat{\eta}, \bar{\eta}$ and $m i g$, and these will cause different adjustments in equilibrium labor amounts. In our simulations we now solve equilibrium values for $\eta^{*}, \hat{\eta}$, $\bar{\eta}, L_{r}, L_{a}, L_{s}, K, w_{r}, w_{a}, w_{s}$, and $m i g$.

Results from these simulations are illustrated in Figures $12-15$ where we replicate the simulations for no entry of unskilled migrants and baseline levels of unskilled migration that we demonstrate in Figures 7 - 10, and augmenting these with the case of endogenous skill migration where $\epsilon_{a}=0.5$.

As we can observe in Figure 12, there is immediately an equilibrium level of skilled migrants. Skiled migration then rises further as capital growth occurs. From simulating capital growth we have a few more propositions:

7) Endogenous skilled migration attracts greater amounts of unskilled migrants and capital. We can observe magnified increases in unskilled migration in Figure 12. 
Given that the inclusion of skilled migrants magnifies the rise of both computer capital and unskilled migrants, one might wonder if the earlier suggestions of the model hold in this case:

8) Points 2-5 raised above remain consistent with skilled migration. While quantitative magnitudes may differ, the overall patterns on native employment and earnings from unskilled migration remain the same as before. First, technological growth attracts unskilled migrants. In fact, this growth creates an even greater attraction, as skilled migrants flow in as well, and these workers further attract unskilled workers. This is due to capitalskill complementarities — skilled labor increases further drive capital increases, which in turn increases the demand for services provided by immigrants.

Next, migrants help natives reverse de-routinization. We can observe this in Figure 13. While the flow of skilled workers tends to shift up routine-labor supply, unskilled migration still partially reverses the outflow of natives from routine jobs.

It is also still the case that unskilled immigration raises the earnings for routine and analytical native workers, and that unskilled immigration helps natives upgrade to analytical tasks (Figure 14). Note however that the inclusion of skilled migrants shift this curves down. If migrants include both skilled and unskilled workers, the net impact of these migrants on native earnings and skills can be ambiguous.

Finally, including skilled migrants also complicates welfare considerations (Figure 15). Now analytically skilled natives also face pecuniary externalities. While overall capital growth is further enhanced with skilled migrants, the initial inflow of analytical workers lowers overall welfare. In our baseline case we see that welfare over 30 periods with both types of migrants will be the same as the case with no migrants at all.

\section{Conclusions}

In this paper, we provide new empirical evidence, and a theoretical explanation, of the immigration response to computer-driven productivity growth, as well as new insights on how the productive specialization of migrants has helped reshape computer-driven polarization.

Empirically, we show that immigration increased in commuting zones where computer- 
intensive growth was stronger between 1980 and 2010. The results hold even when we include a large set of CZs controls. The pull effect was especially strong on low-skilled immigration. Then we show that computerization has produced increased employment in manual and service jobs, but only among immigrants, while natives experienced much less of that effect while still declining in routine-jobs and increase in cognitive-jobs as effect of computerization. Immigration, therefore, may have slowed native job polarization at the low end of the wage distribution. Immigration effects on polarization at the high end of the native skill spectrum are less clear.

We rationalize these facts in a general equilibrium model with three tasks and an exogenous decline in the price of capital. Our main contribution is to augment the traditional model of job polarization with the possibility of an endogenous supply of low-skilled immigrants, who flow in the country in response to higher manual/service wages, and with heterogeneity in productivity of low skilled workers. Immigrants are different from natives in their larger relative productivity in manual services. The model simulations indicate several novel facts that are in line with the empirical evidence. First, computerization attracts low-skilled migrants, and this in turn tends to attenuate the downgrading of natives from routine to service jobs. Computerization produces a weaker polarization of native employment and wages, especially at low skill levels, when immigrants respond to it. And unskilled immigration in particular enhances native welfare.

These results may have important implications for policy. Growing anti-immigrant sentiments in the US and in Europe occur along with ever increasing labor market polarization. Our model indicates that while immigrants are attracted by technological advances and may compete with natives in manual intensive occupations, their general equilibrium effects on the economy is that of attenuating job and wage polarization for natives. This is because they complement native skills, have larger elasticity of response to demand of manual jobs and because they increase demand for goods produced. Policies aimed at reducing immigration inflows, especially of low skilled, can have the unintended consequences of weakening capital accumulation while simultaneously exacerbating native job and wage polarization. Such policies often allege to assist middle-class Americans; they may do precisely the opposite. 


\section{References}

[1] Acemoglu, D. 1998. "Why Do New Technologies Complement Skills? Directed Technical Change and Wage Inequality." The Quarterly Journal of Economics, 113(4): 1055-1089

[2] Acemoglu, D. 2002. "Directed Technical Change." The Review of Economic Studies, 69(4): 781-809.

[3] Acemoglu, D. and D. Autor. 2011. "Skills, Tasks and Technologies: Implications for Employment and Earnings." Handbook of Labor Economics, 4b: 1043-1171 .Elsevier B.V..

[4] Acemoglu, D. and P. Restrepo. 2016. "The Race Between Machine and Man: Implications of Technology for Growth, Factor Shares and Employment," NBER working paper No. 22252.

[5] Acemoglu, D. and P. Restrepo. 2017. "Robots and Jobs: Evidence from US Labor Markets," NBER working paper 23285.

[6] Autor, D.H. 2011. "The polarization of job opportunities in the U.S. labor market: implications for employment and earnings," Community Investments, Federal Reserve Bank of San Francisco, issue Fall, pages 11-16, 40-41.

[7] Autor, D.H. 2015. "Why Are There Still So Many Jobs? The History and Future of Workplace Automation," Journal of Economic Perspectives, 29(3), 330.

[8] Autor, D.H., and D. Dorn. 2013. "The Growth of Low-Skill Service Jobs and the Polarization of the U.S. Labor Market," American Economic Review 103(5): 1553-1597.

[9] Autor, D.H., D. Dorn, and G. H. Hanson. 2015. "Untangling Trade and Technology: Evidence from Local Labor Markets," Economic Journal 125: 621-646.

[10] Autor, D.H., F. Levy and R.J. Murnane . 2003. "The Skill Content of Recent Technological Change: An Empirical Exploration," The Quarterly Journal of Economics 118(4): 1279-1334.

[11] Bartik, T.J. 1991. Who Benefits from State and Local Economic Development Policies?. Kalamazoo, MI: W.E. Upjohn Institute for Employment Research.

[12] Basso, G. and G. Peri, 2015. "The Association between Immigration and Labor Market Outcomes in the United States," IZA Discussion Paper No. 9436.

[13] Beaudry, P., M. Doms M. and E. Lewis. 2010. "Should the personal computer be considered a technological revolution? Evidence from US metropolitan areas," Journal of Political Economy 118(5): 988-1036.

[14] Borjas, G.J. 2001. "Does Immigration Grease the Wheels of the Labor Market?," Brookings Papers on Economic Activity, Economic Studies Program, The Brookings Institution, vol. 32(1), pages 69-134. 
[15] Borjas, G.J. 2014. "Immigration Economics" Harvard University Press, Cambridge Mass.

[16] Bound, J., G. Khanna and N. Morales, 2018. "Understanding the Economic Impact of the H-1B Program on the US," in High-Skilled Migration to the United States and its Economic Consequences, G.H. Hanson, W.R. Kerr and S. Turner (Eds.). University of Chicago Press.

[17] Cadena, B. and B. Kovak. 2016. "Immigrants Equilibrate Local Labor Markets: Evidence from the Great Recession." American Economic Journal: Applied Economics, $8(1): 257-90$.

[18] Card, D. 2001. "Immigrant Inflows, Native Outflows, and the Local Labor Market Impacts of Higher Immigration." Journal of Labor Economics 19(1):22-64.

[19] Card, D. 2009. "Immigration and Inequality." American Economic Review, 99(2):1-21.

[20] Card, D. and G. Peri. 2016. "Immigration Economics by George J. Borjas: A Review Essay." Journal of Economic Literature, 54(4):1333-49.

[21] Cerina, F., A. Moro, and M. Petersen Rendall. 2017. "The Role of Gender in Employment Polarization." University of Zurich, Department of Economics, Working Paper Series No. 250.

[22] Civale, S. 2016. "Has the Decline in the Price of Investment Increased Wealth Inequality." University of Minnesota working paper.

[23] Clemens, M.A., E.G. Lewis, H.M. Postel. 2018. "Immigration restrictions as active labor market policy: Evidence from the Mexican Bracero Exclusion," American Economic Review, 108(6): 1468-1487.

[24] Diamond, R. 2016. "The Determinants and Welfare Implications of US Workers' Diverging Location Choices by Skill: 1980-2000." American Economic Review, 106(3):479-524.

[25] Galor, O. and O. Moav. 2000. "Ability-Biased Technological Transition, Wage Inequality, and Economic Growth." The Quarterly Journal of Economics, 115(2):469497.

[26] Goos, M., A. Manning, and A. Salomons. 2014. "Explaining Job Polarization: Routine-Biased Technological Change and Offshoring." American Economic Review, 104(8):2509-2526.

[27] Gordon, R. 1990. The Measurement of Durable Goods Prices. National Bureau of Economic Research, Inc.

[28] Grogger, J. and G.H.Hanson. 2011. "Income maximization and the selection and sorting of international migrants," Journal of Development Economics, 95(1): 42-57.

[29] Hunt, J. 2016. "The Impact of Immigration on the Educational Attainment of Natives." The Journal of Human Resources, forthcoming. 
[30] Jaimovich, N. and H.E. Siu. 2018. "High-Skilled Immigration, STEM Employment, and Non-Routine-Biased Technical Change," in High-Skilled Migration to the United States and its Economic Consequences, G.H. Hanson, W.R. Kerr and S. Turner (Eds.). University of Chicago Press.

[31] Lewis, E. 2011. "Immigration, Skill Mix, and Capital-Skill Complementarity." Quarterly Journal of Economics 126(2): 1029-1069.

[32] Lewis, E. 2013. "Immigration and Production Technology," Annual Review of Economics (5).

[33] Llull, J. 2018. "Immigration, Wages, and Education: A Labor Market Equilibrium Structural Model," The Review of Economic Studies, 85(3): 1852-1896.

[34] Mandelman, F. and A. Zlate. 2014. "Offshoring, Low-Skilled Immigration, and Labor Market Polarization," Atlanta FED, Working Paper 2014-28.

[35] Mayda, A. 2010. "International migration: a panel data analysis of the determinants of bilateral flows," Journal of Population Economics, Springer; European Society for Population Economics, vol. 23(4), pages 1249-1274, September.

[36] Mazzolari, F. and G. Ragusa. 2013 "Spillovers from High-Skill Consumption to LowSkill Labor Markets," The Review of Economics and Statistics, 95(1):74-86.

[37] Moretti, E. 2013. "Real Wage Inequality." American Economic Journal: Applied Economics, 5(1): 65-103.

[38] Ottaviano, G.I.P. and G. Peri. 2012. "Rethinking the Effect of Immigration on Wages." Journal of European Economic Association 10(1): 152-197.

[39] Peri, G. 2008. "International Migrations: Some Comparisons and Lessons for the EU" in The European Economy is an American Mirror, B. Eichengreen, M. Landesmann, and D. Stiefel, editors. Routledge, Taylor and Francis: Oxford, UK.

[40] Peri, G. 2016. "Immigrants, Productivity, and Labor Markets," Journal of Economic Perspectives, American Economic Association, vol. 30(4), pages 3-30, Fall.

[41] Peri, G. and C. Sparber. 2009. "Task Specialization, Immigration and Wages." American Economic Journal: Applied Economics, 1(3): 135-169.

[42] Ruggles, S., K. Genadek, R. Goeken, J. Grover, and M. Sobek. 2015. Integrated Public Use Microdata Series: Version 6.0 [Machine-readable database]. Minneapolis: University of Minnesota.

[43] Tolbert, C. and M. Sizer. 1996. "U.S. commuting zones and Labor Market Areas: A 1990 Update." ERS Staff Paper Number 9614. Economic Research Service, Rural Economy Division, U.S. Department of Agriculture, Washington, D.C.

[44] US Department of Labor. 1977. "Dictionary of Occupational Titles," 4th ed. Washington, DC: US Government Printing Office. 
[45] Waugh, M.E., 2018. "Firm Dynamics and Immigration: The Case of High-Skilled Immigration," in High-Skilled Migration to the United States and its Economic Consequences, G.H. Hanson, W.R. Kerr and S. Turner (Eds.). University of Chicago Press. 


\section{Figures}

Figure 1: Correlation: CPS-Based PC Use and AD's Routine Share $(R S H)$

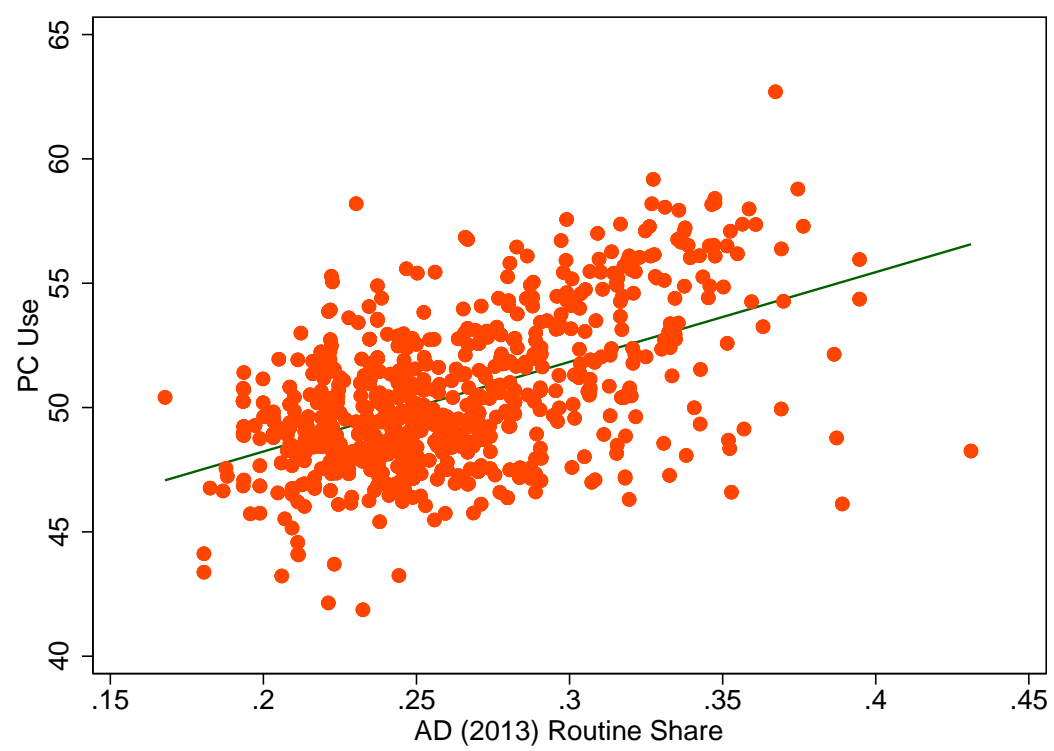

Note: Correlation between the CPS-based PC use measure and the Routine Share of Autor and Dorn (2013). The unweighted regression coefficient is 36.1 and it is statistically significant at .01 percent. 
Figure 2: Correlation: CPS-Based PC Use and BDL's (2010) Firm-Level PC Adoption

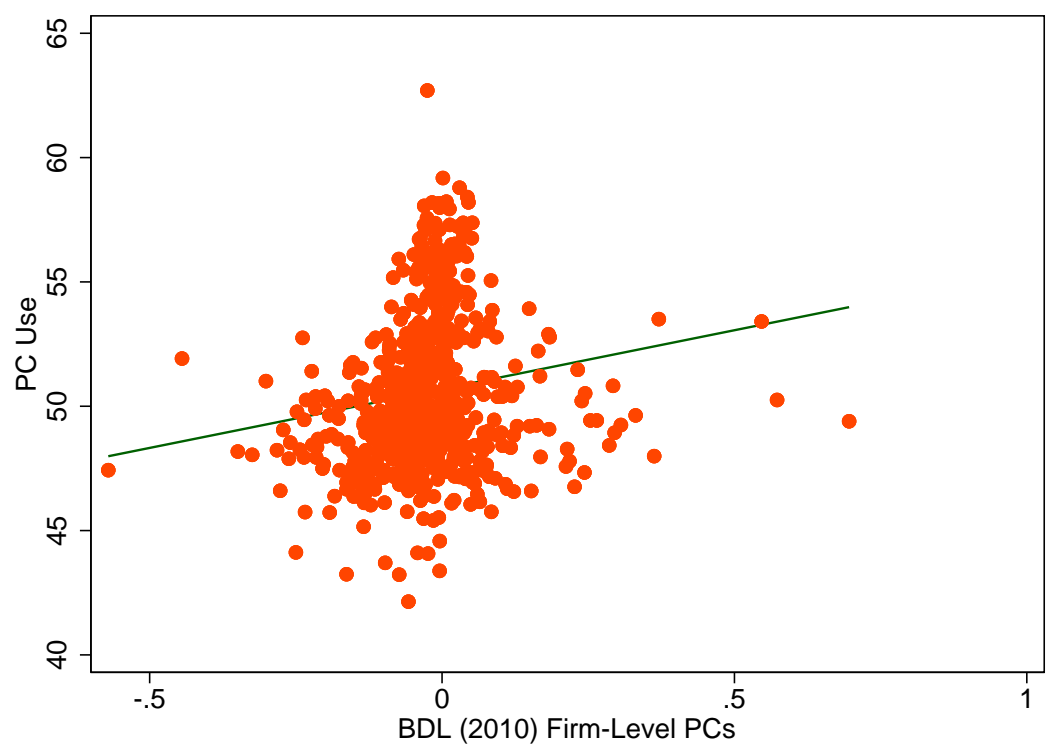

Note: Correlation between the CPS-based PC use measure and the firm-level PC adoption of Beaudry, Doms and Lewis (2010). The unweighted regression coefficient is 4.7 and it is statistically significant at .01 percent. 
Figure 3: US and Foreign-born Task Supply, 1980-2010

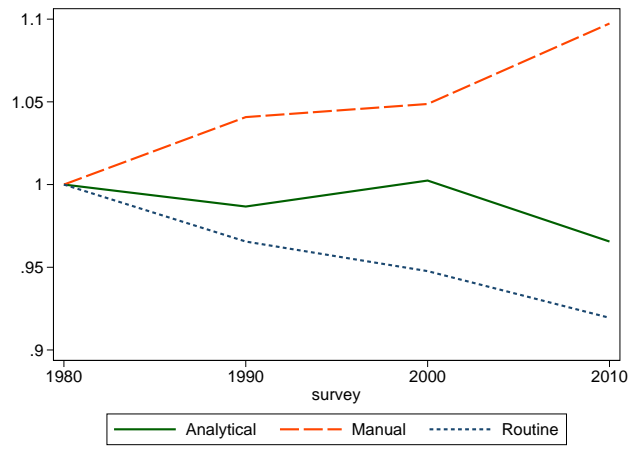

(a) Low-skilled Foreign Born

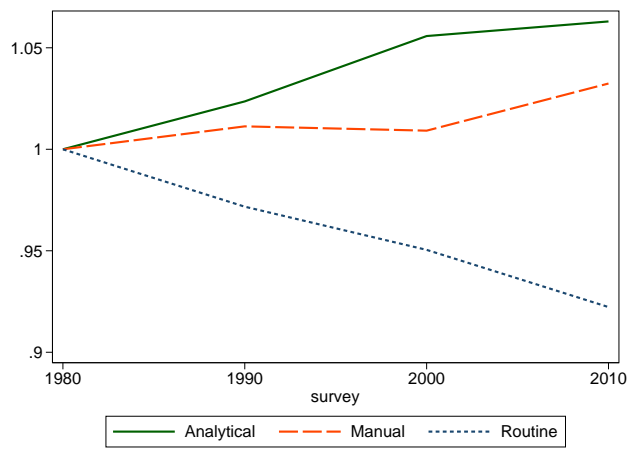

(c) Low-skilled Natives

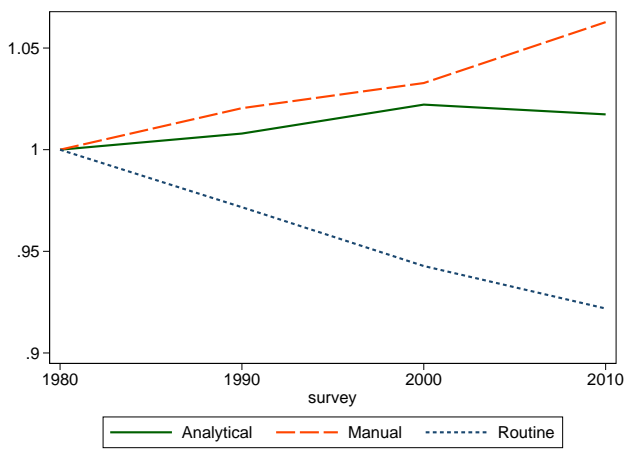

(b) High-skilled Foreign Born

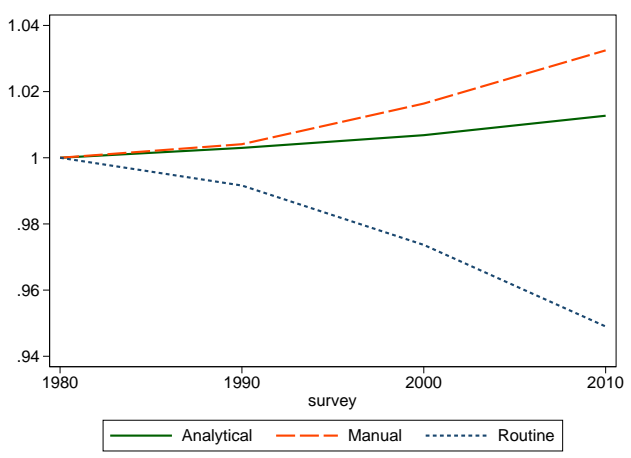

(d) High-skilled Natives

Note: panel 3a and 3b plots the task supply of foreign born (as share of total supply) by skill level; panel 3c and $3 \mathrm{~d}$ plots the same measure for natives. 
Figure 4: Smoothed Changes of Foreign-born and Natives' Own Group Employment by Skill Percentile 1980-2010

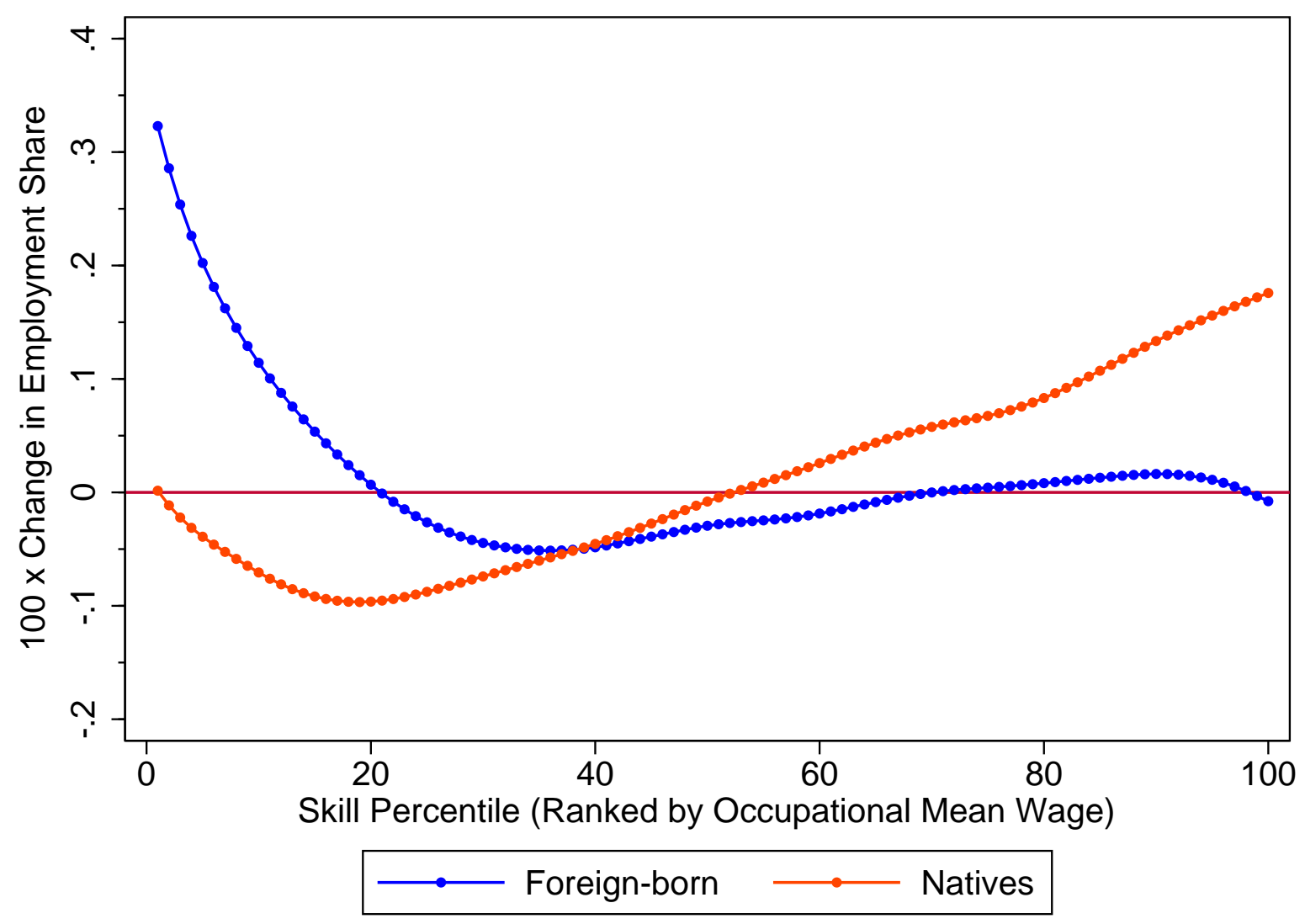


Figure 5: Smoothed Changes of Foreign-born and Natives'

Employment over Total by Skill Percentile 1980-2010

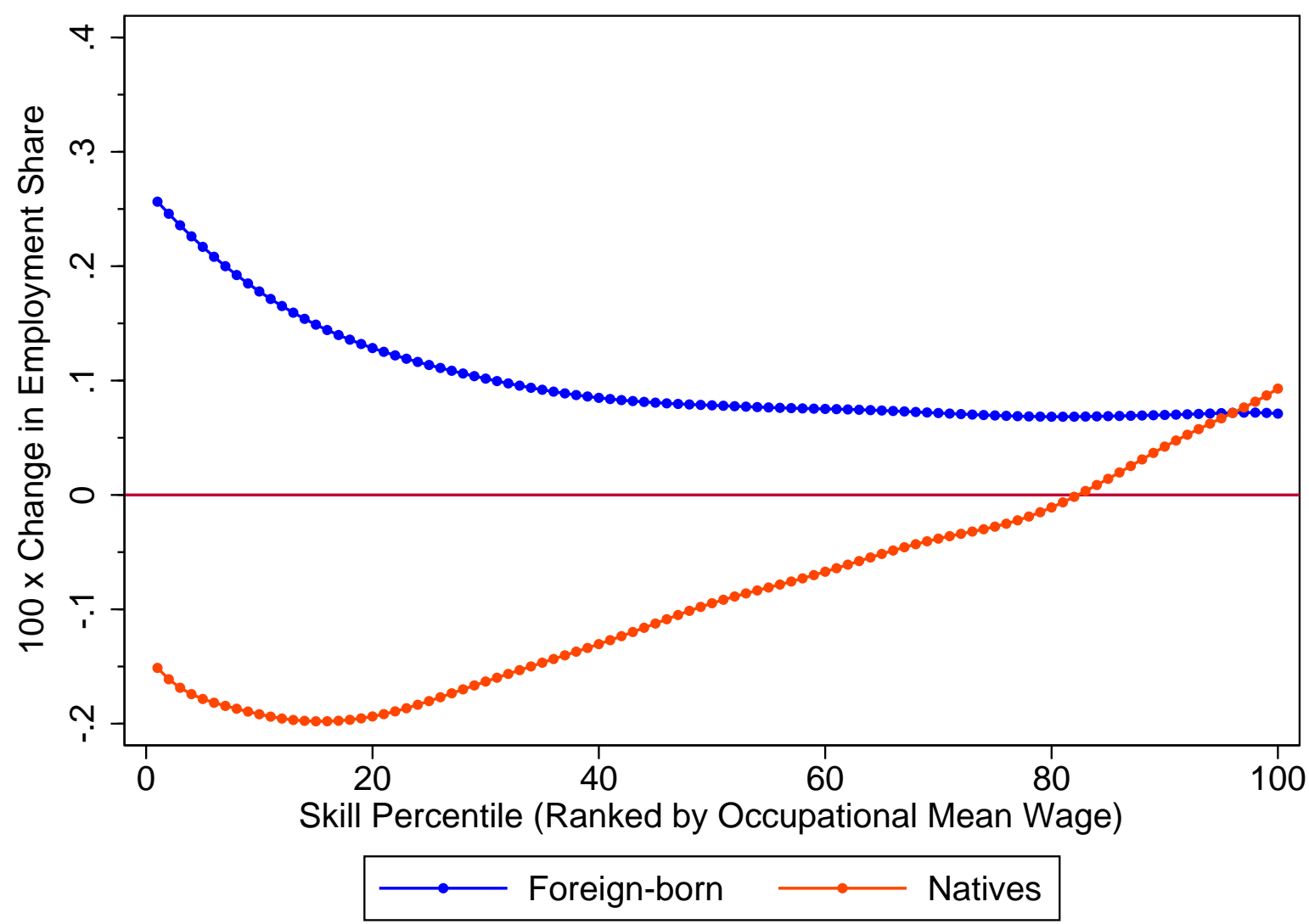

Note: The above decomposition differs from that of Figure 4 because the employment shares are calculated over the entire US employment (natives and foreign born): for each percentile $p$,

$\frac{E_{210}^{p}}{E_{2010}^{p}+E_{2010}^{p}}-\frac{E_{1980}^{p}}{E_{1980}^{p}+E_{1980}^{p}}=\frac{E_{f b, 2010}^{p}}{E_{f b, 2010}^{p}+E_{U S, 2010}^{p}}-\frac{E_{f b, 1980}^{p}}{E_{f b, 2010}^{p}+E_{U S, 1980}^{p}}+$ $\frac{E_{U S, 2010}^{p}}{E_{f b, 2010}^{p}+E_{U S, 2010}^{p}}-\frac{E_{U S, 1980}^{p}}{E_{f b, 1980}^{p}+E_{U S, 1980}^{p}}$ 
Figure 6: Changes in Native Employment Levels from Higher Computerization

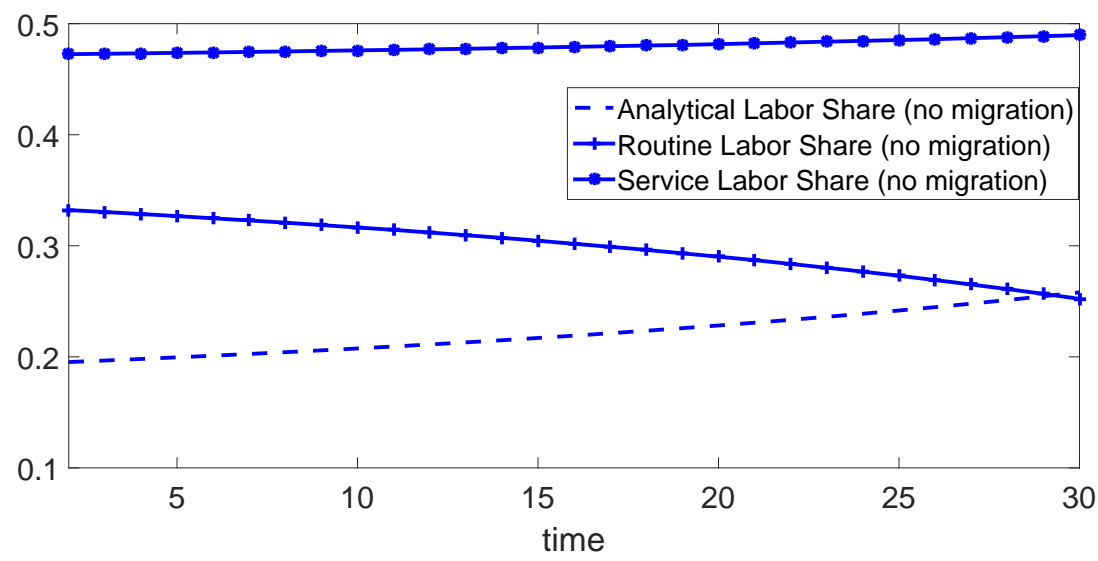

Note: Simulation of model dynamics holding $\varepsilon=0$.

Figure 7: Changes in Unskilled Migrants from Higher Computerization

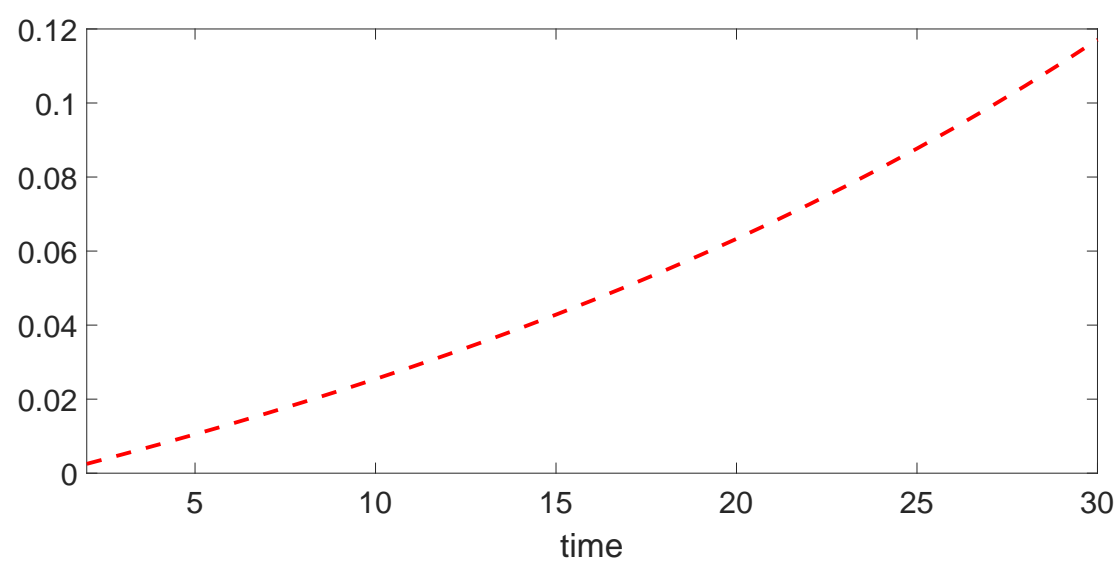

Note: Simulation of model dynamics for $\varepsilon=0.2\}$. 
Figure 8: Changes in Native Routine Employment Levels from Higher Computerization and Immigration

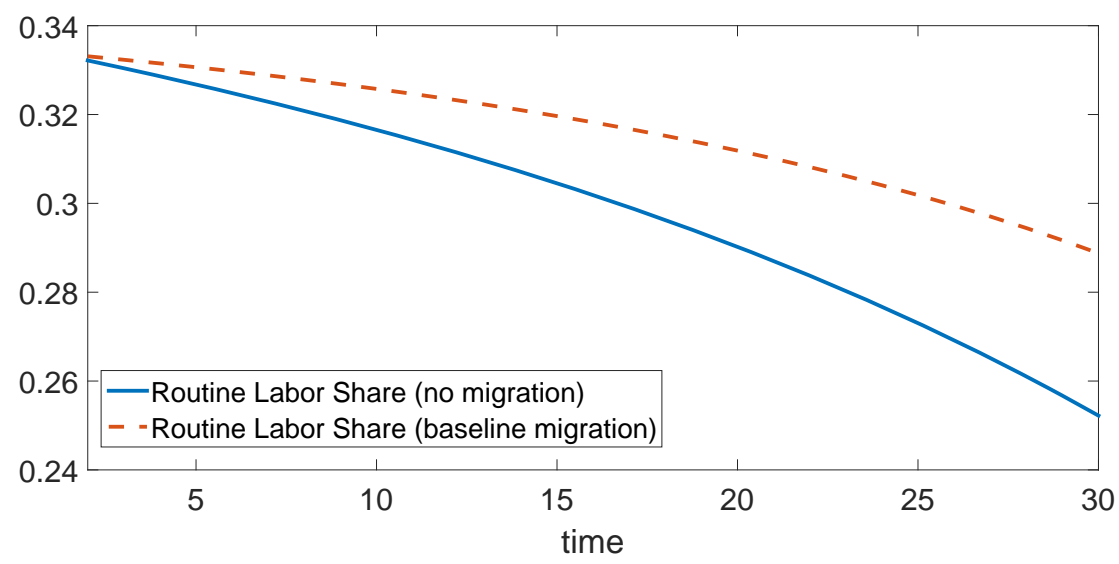

Note: Simulation of model dynamics for $\varepsilon=\{0.2\}$.

Figure 9: Changes in Native Analytical Employment from Higher Computerization and Immigration

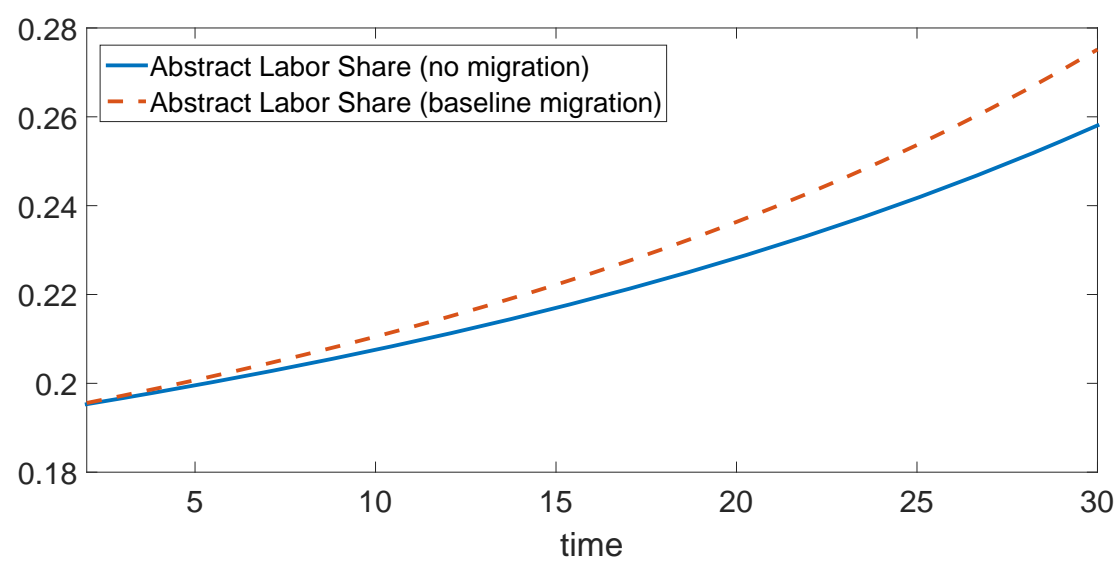

Note: Simulation of model dynamics for $\varepsilon=\{0.2\}$. 
Figure 10: Representation of the Partial Equilibrium

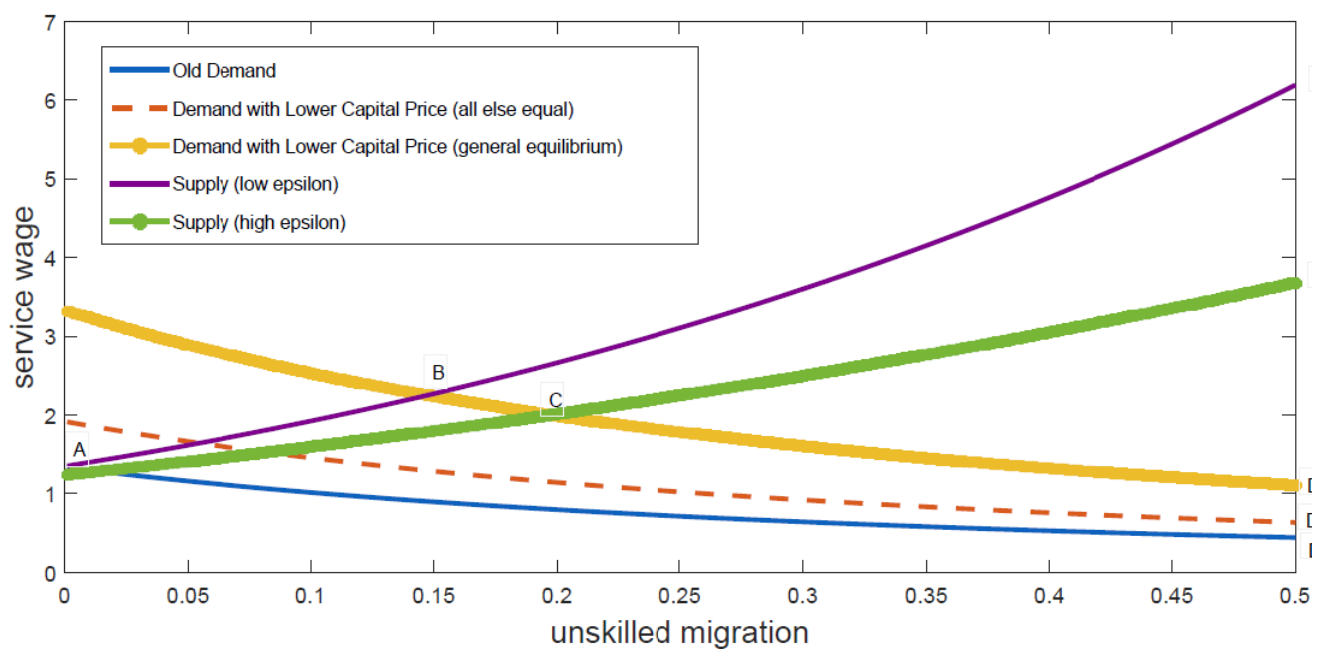

Note: Partial equilibrium in the service wage-migration space.

Figure 11: Changes in Aggregate Native Utility from Higher Computerization and Immigration

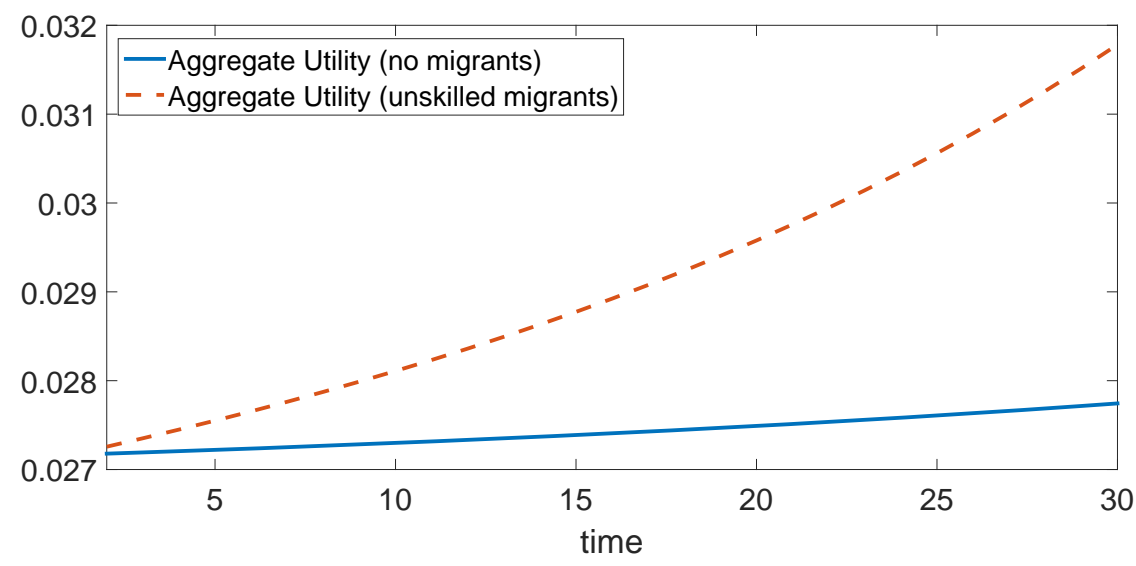

Note: Simulation of model dynamics for $\varepsilon=\{0.2\}$. 
Figure 12: Changes in Skilled and Unskilled Migrants from Higher Computerization

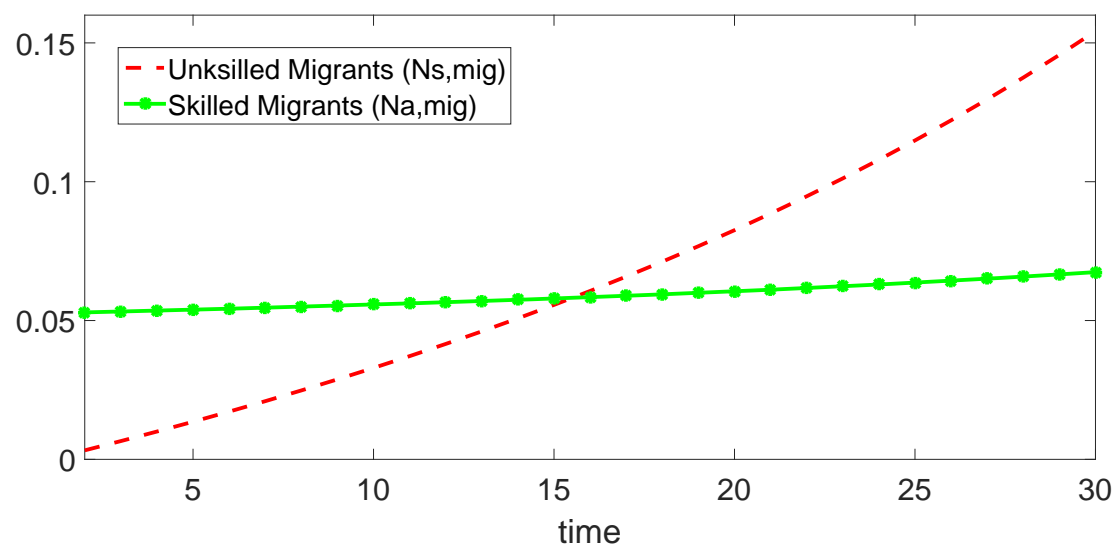

Note: Simulation of model dynamics for $\varepsilon=0.2\}$ and $\left.\varepsilon_{a}=0.5\right\}$.

Figure 13: Changes in Native Routine Employment Levels from Higher Computerization and Low \& High-Skilled Immigration

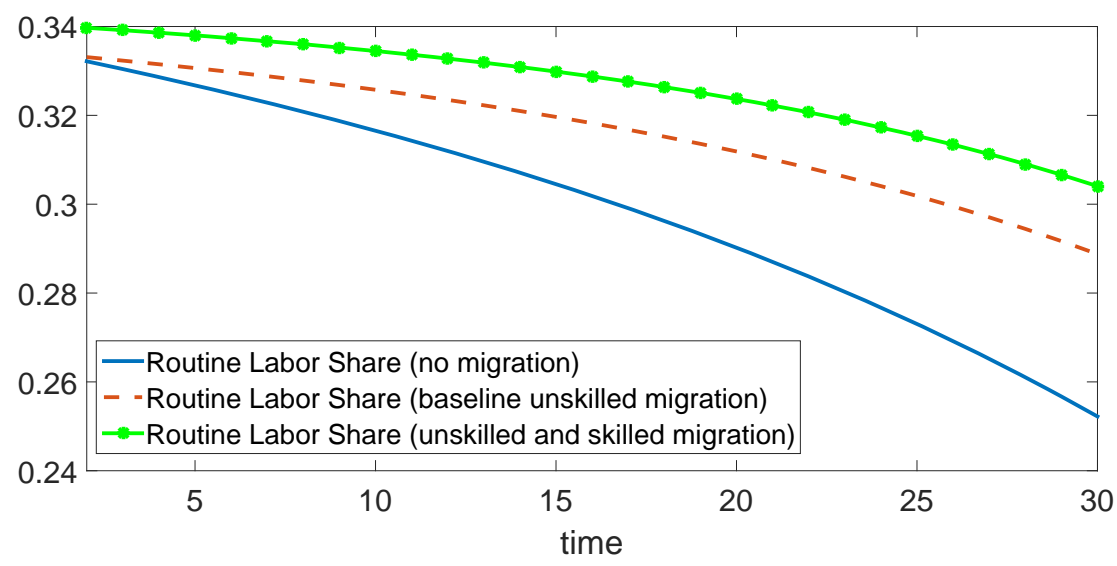

Note: Simulation of model dynamics for $\varepsilon=0.2\}$ and $\left.\varepsilon_{a}=0.5\right\}$. 
Figure 14: Changes in Native Analytical Employment from Higher Computerization and Low \& High-Skilled Immigration

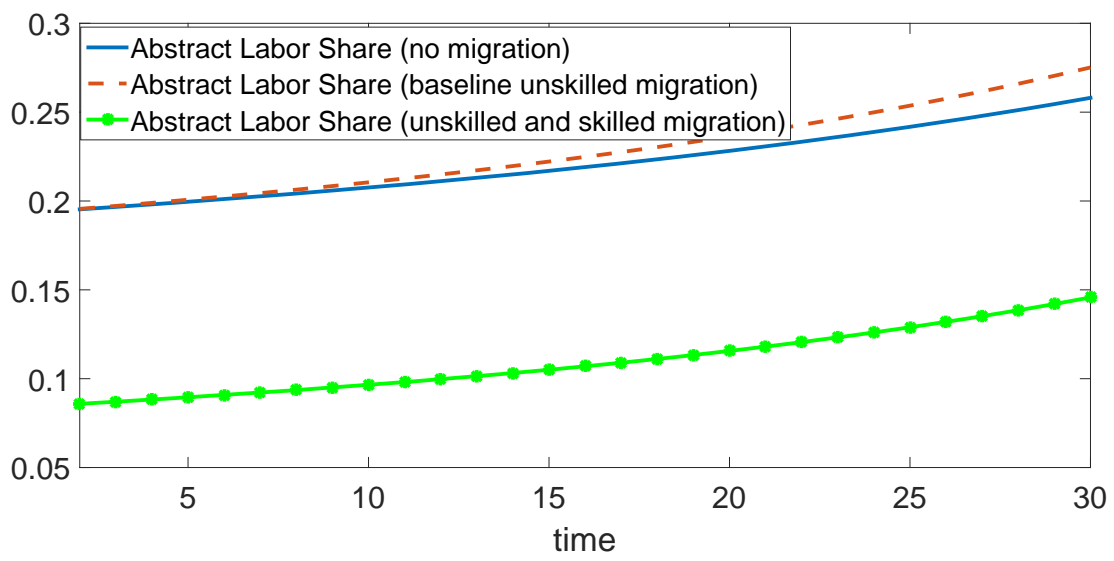

Note: Simulation of model dynamics for $\varepsilon=0.2\}$ and $\left.\varepsilon_{a}=0.5\right\}$.

Figure 15: Changes in Native Aggregate Utility from Computerization and Both Types of Migration

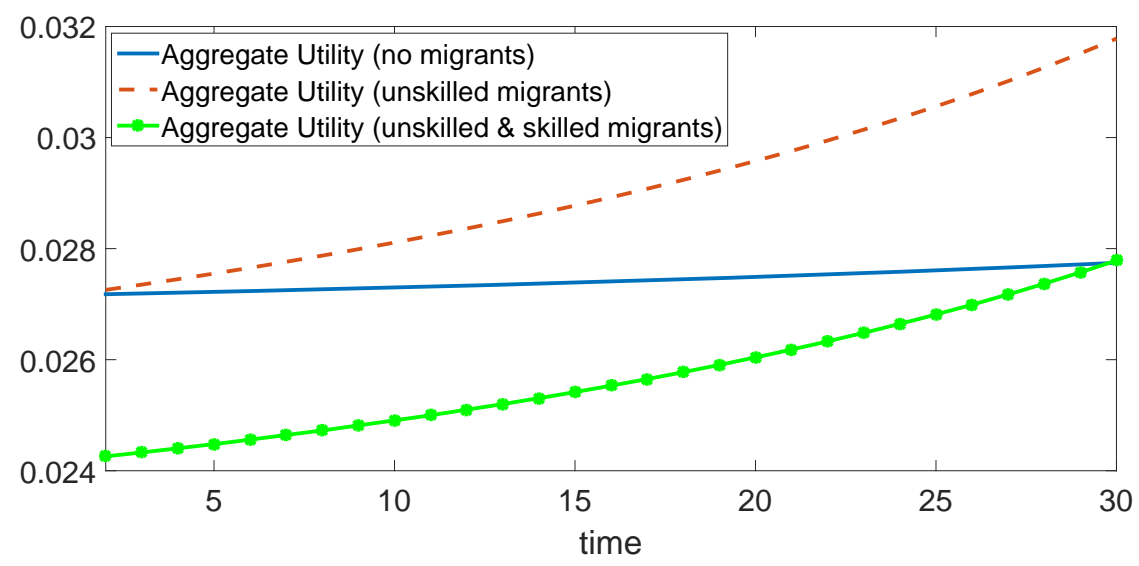

Note: Simulation of model dynamics for $\varepsilon=0.2\}$ and $\left.\varepsilon_{a}=0.5\right\}$. 


\section{Tables}

Table 1: Correlations between PC Use and Beaudry, Doms and Lewis' (2010) Firm-level PCs

\begin{tabular}{lcccc}
\hline \hline & $(1)$ & $(2)$ & $(3)$ & $(4)$ \\
\hline Firm-level PC use (BDL 2010) & $4.734^{* *}$ & $31.813^{* *}$ & $25.959^{* *}$ & $17.061^{* *}$ \\
& $(1.403)$ & $(5.370)$ & $(3.416)$ & $(2.732)$ \\
Labor Productivity & & & & \\
& & & & $1.893^{* *}$ \\
\hline State FE & - & - & $\mathrm{Y}$ & $\mathrm{Y}$ \\
Weighted & - & $\mathrm{Y}$ & $\mathrm{Y}$ & $\mathrm{Y}$ \\
Labor Product. & 660 & 660 & 660 & 660 \\
Obs. & 0.0 & 0.2 & 0.6 & 0.8 \\
\hline \hline
\end{tabular}

Note: The sample is composed of $660 \mathrm{CZs}$ matched to the original $230 \mathrm{CMSA}$ of Beaudry, Doms and Lewis (2010). Standard errors (in parentheses) are clustered at the state level. All regressions include a constant.

$* *, * *,+$ indicate significance at 1-percent, 5-percent and 10-percent level, respectively. 
Table 2: US and Foreign Born Population and PC Adoption, 1980-2010

\begin{tabular}{|c|c|c|}
\hline & ow Skille & igh Skilled \\
\hline Panel $A$ & Natives & \\
\hline PC use & 0.219 & $2.419^{* *}$ \\
\hline & $(0.314)$ & $(0.641)$ \\
\hline Obs. & 722 & 722 \\
\hline $\mathrm{R} 2$ & 0.64 & 0.55 \\
\hline Panel B & Foreign & \\
\hline$\overline{\mathrm{PC}}$ use & $0.555^{+}$ & $1.038^{* *}$ \\
\hline & $(0.299)$ & $(0.210)$ \\
\hline Obs. & 722 & 722 \\
\hline $\mathrm{R} 2$ & 0.67 & 0.79 \\
\hline $\begin{array}{l}\text { Vote: The } \\
\text { observed } \\
\text { Standard } \\
\text { at the stat } \\
\text { by the be } \\
\text { Each colu } \\
(2) \text { and }\end{array}$ & $\begin{array}{l}\text { ple is co } \\
\text { een } 1980 \\
\text { s (in pare } \\
\text { el. All reg } \\
\text { ing of de } \\
\text { reports th } \\
\text { All regres }\end{array}$ & $\begin{array}{l}\text { of } 722 \mathrm{CZs} \\
10(\mathrm{~N}=722) \\
\text { are clustered } \\
\text { are weighted } \\
\mathrm{Z} \text { population. } \\
\text { om equations } \\
\text { aclude a con- } \\
\text { at 1-percent, } \\
\text { respectively. }\end{array}$ \\
\hline
\end{tabular}


Table 3: US and Foreign Born Population and PC Adoption, 1950-1980 (pre-trends)

\begin{tabular}{|c|c|c|}
\hline & w Skill & Shilled \\
\hline Panel $A$ & Natives & \\
\hline $\mathrm{PC}$ use & $\begin{array}{c}6.559 \\
(3.999) \\
\end{array}$ & $\begin{array}{l}8.654^{*} \\
(4.150) \\
\end{array}$ \\
\hline Obs. & 722 & 722 \\
\hline $\mathrm{R} 2$ & 0.53 & 0.54 \\
\hline Panel B & Foreign & \\
\hline$\overline{\mathrm{PC}}$ use & $\begin{array}{c}1.543 \\
(1.706)\end{array}$ & $\begin{array}{c}1.226 \\
(0.890)\end{array}$ \\
\hline Obs. & 722 & 722 \\
\hline $\mathrm{R} 2$ & 0.53 & 0.53 \\
\hline $\begin{array}{l}\text { Vote: The } \\
\text { observed b } \\
\text { Standard e } \\
\text { at the state } \\
\text { by the beg } \\
\text { Each colur } \\
\text { (4). All r } \\
\text { state fixed }\end{array}$ & $\begin{array}{l}\text { ple is co } \\
\text { een } 1950 \\
\text { (in pare } \\
\text { el. All rę } \\
\text { ing of de } \\
\text { eeports t } \\
\text { ssions inc } \\
\text { cts. }\end{array}$ & $\begin{array}{l}\text { of } 722 \mathrm{CZs} \\
980(\mathrm{~N}=722) \\
\text { are clustered } \\
\text { s are weighted } \\
\mathrm{Z} \text { population. } \\
\text { rom equation } \\
\text { constant and } \\
\text { at 1-percent, } \\
\text { respectivelv, }\end{array}$ \\
\hline
\end{tabular}


Table 4: US and Foreign Born Employment and PC Adoption, 1980-2010

\begin{tabular}{|c|c|c|}
\hline & „ow Skille & igh Skilled \\
\hline Panel $A$ & Natives & \\
\hline PC use & 0.115 & $2.047^{* *}$ \\
\hline & $(0.304)$ & $(0.635)$ \\
\hline Obs. & 722 & 722 \\
\hline R2 & 0.59 & 0.52 \\
\hline Panel B & Foreign & \\
\hline$\overline{\mathrm{PC} \text { use }}$ & 0.416 & $1.008^{* *}$ \\
\hline & $(0.301)$ & $(0.199)$ \\
\hline Obs. & 722 & 722 \\
\hline $\mathrm{R} 2$ & 0.66 & 0.79 \\
\hline $\begin{array}{l}\text { Note: The } \\
\text { observed b } \\
\text { Standard e } \\
\text { at the state } \\
\text { by the beg } \\
\text { Each colun } \\
\text { (2) and (3 } \\
\text { stant and s } \\
* *, * *,+ \\
5 \text {-percent a }\end{array}$ & $\begin{array}{l}\text { mple is col } \\
\text { tween } 1980 \\
\text { ors (in paren } \\
\text { evel. All reg } \\
\text { aning of dec } \\
\text { reports th } \\
\text { All regres } \\
\text { ate fixed effe } \\
\text { dicate signi } \\
\text { d 10-percent }\end{array}$ & $\begin{array}{l}\text { d of } 722 \mathrm{CZs} \\
2010 \text { ( } \mathrm{N}=722) \text {. } \\
\text { s) are clustered } \\
\text { ns are weighted } \\
\mathrm{CZ} \text { population. } \\
\text { from equations } \\
\text { include a con- } \\
\text { e at 1-percent, } \\
\text { l, respectively. }\end{array}$ \\
\hline
\end{tabular}

Table 5: Average Task Specialization Indexes by Occupation in 1980

\begin{tabular}{lccc}
\hline \hline & $\begin{array}{c}\text { Analytical/ } \\
\text { Cognitive }\end{array}$ & Routine & $\begin{array}{c}\text { Manual/ } \\
\text { Communication }\end{array}$ \\
\hline Managers/prof/tech & 0.807 & 0.343 & 0.478 \\
Clerical/sales/operators & 0.415 & 0.664 & 0.358 \\
Services/construct/transp & 0.322 & 0.451 & 0.737 \\
\hline Average Specialization & 0.493 & 0.505 & 0.517 \\
\% of Total & $32 \%$ & $34 \%$ & $34 \%$ \\
\hline \hline
\end{tabular}

Note: The task indexes reflect the specialization of the three broad occupational groups (rows) showing the share of workforce using less of that task on the job. Please refer to the main text for more details. 
Table 6: Foreign-born and Natives' Task Specialization Indexes, Shares over Total, 1980-2010

\begin{tabular}{lccc}
\hline \hline & Analytical & Manual & Routine \\
\hline Panel A. Foreign-born & & & \\
\hline 1980 & 0.292 & 0.353 & 0.355 \\
2010 & 0.313 & 0.367 & 0.319 \\
\hline Delta \% & 7.19 & 3.97 & -10.14
\end{tabular}

\begin{tabular}{lccc} 
Panel B. Natives & & & \\
\hline 1980 & 0.321 & 0.339 & 0.340 \\
2010 & 0.370 & 0.331 & 0.299 \\
\hline Delta \% & 15.26 & -2.36 & -12.06 \\
\hline \hline
\end{tabular}

Note: Please refer to Table 5 and the main text for more details.

Table 7: Occupational Employment Shares among Natives and Foreign Born, 1980-2010

\begin{tabular}{lccc}
\hline \hline Prevalently & $\begin{array}{c}\text { Managers/prof/tech } \\
\text { Analytical/Cognitive }\end{array}$ & $\begin{array}{c}\text { Clerical/sales/operators } \\
\text { Routine }\end{array}$ & $\begin{array}{c}\text { Services/construct/transp } \\
\text { Manual }\end{array}$ \\
\hline Panel A: Natives & 0.276 & 0.409 & 0.315 \\
1980 & 0.405 & 0.304 & 0.292 \\
2010 & 0.129 & -0.106 & -0.023 \\
\hline Delta & 0.241 & 0.420 & 0.339 \\
Panel B: Foreign born & 0.294 & 0.250 & 0.456 \\
\hline 1980 & 0.053 & -0.169 & 0.116 \\
2010 & \multicolumn{2}{c}{ more details. }
\end{tabular}


Table 8: US and Foreign Born Task Specialization and PC Adoption, 1980-2010

\begin{tabular}{|c|c|c|c|}
\hline & Ianual Ta & outine $\mathrm{Ta}$ & alytical Task \\
\hline Panel $A$ & Natives & & \\
\hline PC use & $0.113^{* *}$ & $-0.255^{* *}$ & $0.142^{* *}$ \\
\hline & $(0.016)$ & $(0.025)$ & $(0.036)$ \\
\hline Obs. & 722 & 722 & 722 \\
\hline $\mathrm{R} 2$ & 0.57 & 0.74 & 0.52 \\
\hline Panel B & Foreign & & \\
\hline$\overline{\mathrm{PC}}$ use & $0.130^{+}$ & $-0.208^{* *}$ & 0.078 \\
\hline & $(0.066)$ & $(0.068)$ & $(0.104)$ \\
\hline Obs. & 722 & 722 & 722 \\
\hline $\mathrm{R} 2$ & 0.43 & 0.40 & 0.54 \\
\hline $\begin{array}{l}\text { Note: } \text { The } \mathrm{s} \\
2010(\mathrm{~N}=7 \\
\text { state level. } \\
\mathrm{CZ} \text { populat } \\
\text { regressions } \\
* *, * *,+\mathrm{i} \\
\text { level, respe }\end{array}$ & $\begin{array}{l}\text { nple is comp } \\
\text { ). Standard } \\
\text { All regressio } \\
\text { n. Each co } \\
\text { clude a cons } \\
\text { dicate signifi } \\
\text { ively. }\end{array}$ & $\begin{array}{l}f 722 \mathrm{CZs} \text { ol } \\
\text { (in parenth } \\
\text { weighted by } \\
\text { eports the } \beta \\
\text { d state fixed } \\
\text { at } 1 \text {-percent, }\end{array}$ & $\begin{array}{l}\text { between } 1980 \text { and } \\
\text { clustered at the } \\
\text { pinning of decade } \\
\text { equation (4). All } \\
\text { th and 10-percent }\end{array}$ \\
\hline
\end{tabular}

Table 9: US and Foreign Born Occupational Employment Shares and PC Adoption, 1980-2010

\begin{tabular}{|c|c|c|c|}
\hline & v/Trans & Ret/Pro & $\mathrm{ag} /$ Prof Occ \\
\hline Panel $A$ & Tatives & & \\
\hline PC use & $\begin{array}{c}0.088 \\
(0.076)\end{array}$ & $\begin{array}{c}-0.646^{* *} \\
(0.089)\end{array}$ & $\begin{array}{l}0.558^{* *} \\
(0.063)\end{array}$ \\
\hline Obs. & 722 & 722 & 722 \\
\hline R2 & 0.46 & 0.73 & 0.60 \\
\hline Panel B & oreign $B$ & & \\
\hline$\overline{\mathrm{PC}}$ use & $\begin{array}{l}0.441^{+} \\
(0.257)\end{array}$ & $\begin{array}{c}-1.036^{* *} \\
(0.175)\end{array}$ & $\begin{array}{c}0.595^{*} \\
(0.252)\end{array}$ \\
\hline Obs. & 722 & 722 & 722 \\
\hline R2 & 0.43 & 0.41 & 0.51 \\
\hline
\end{tabular}

Note: The sample is composed of $722 \mathrm{CZs}$ observed between 1980 and $2010(\mathrm{~N}=722)$. Standard errors (in parentheses) are clustered at the state level. All regressions are weighted by the beginning of decade $\mathrm{CZ}$ population. Each column reports the $\beta$ s from equation (4). All regressions include a constant and state fixed effects.

$* *, * *,+$ indicate significance at 1-percent, 5-percent and 10-percent level, respectively. 
Table 10: US and Foreign Born Occupational Wages and PC Adoption, 1980-2010

\begin{tabular}{|c|c|c|c|}
\hline 8 & v/Trans & Ret/Prod & agg/Prof Occ \\
\hline Panel $A$ & atives & & \\
\hline PC use & 0.006 & $-0.045^{* *}$ & $0.046^{* *}$ \\
\hline & $(0.005)$ & $(0.006)$ & $(0.004)$ \\
\hline Obs. & 722 & 722 & 722 \\
\hline $\mathrm{R} 2$ & 0.46 & 0.73 & 0.66 \\
\hline Panel $B$ & oreign $B$ & & \\
\hline $\mathrm{PC}$ use & 0.020 & $-0.076^{* *}$ & $0.051^{* *}$ \\
\hline & $(0.016)$ & $(0.011)$ & $(0.018)$ \\
\hline$\overline{\text { Obs. }}$ & 722 & 722 & 722 \\
\hline $\mathrm{R} 2$ & 0.42 & 0.44 & 0.50 \\
\hline $\begin{array}{l}\text { Vote: The s: } \\
\text { Standard e } \\
\text { weighted by } \\
\text { equation }(4 \\
* *, * *,+ \text { i } \\
\text { tively. }\end{array}$ & $\begin{array}{l}\text { e is compos } \\
\text { (in parenth } \\
\text { beginning o } \\
\text { l regressions } \\
\text { te significa }\end{array}$ & $\begin{array}{l}\text { observed be } \\
\text { stered at the } \\
\text { opulation. } \mathrm{E} \\
\text { nstant and s } \\
\text { ent, 5-percer }\end{array}$ & $\begin{array}{l}\text { nd } 2010(\mathrm{~N}=722) \text {. } \\
\text { All regressions are } \\
\text { eports the } \beta \text { s from } \\
\text { cts. } \\
\text { cent level, respec- }\end{array}$ \\
\hline
\end{tabular}

Table 11: Parameter Values in Baseline Simulation

\begin{tabular}{|c|c|c|c|}
\hline & Parameter Value & Justification & Source \\
\hline \multicolumn{4}{|c|}{ Calibrated Values } \\
\hline$\downarrow p_{k}$ & $\begin{array}{c}p_{k, t=1}=4 \\
p_{k, t=30}=2.26\end{array}$ & $\begin{array}{c}\text { Investment good prices } \\
\downarrow 44 \% 1980-2010\end{array}$ & Civale (2016) \\
\hline$\gamma$ & 0.5 & $K, L_{r}$ elas of sub $\approx 2$ & Krussel et al. (2000) \\
\hline$\beta$ & -10 & $X, L_{a}$ elas of sub $\approx 0$ & numerous \\
\hline$\sigma$ & 0.5 & $\begin{array}{l}\text { elas of sub in production }> \\
\text { elas of sub in consumption }\end{array}$ & Autor and Dorn (2013) \\
\hline \multicolumn{4}{|c|}{ "Free" Parameters } \\
\hline$\rho$ & 0.1 & small weight on services & - \\
\hline$p_{a}$ & 0.5 & resource costs to educ & - \\
\hline$\alpha$ & 1.5 & higher weight on skilled workers & - \\
\hline$p_{k, t=1}$ & 4 & initial price of $K$ & - \\
\hline$\epsilon$ & 0.2 & migration responsiveness & - \\
\hline
\end{tabular}


Table 12: Baseline Simulation Results

\begin{tabular}{lcc|c}
\hline \hline Variables & $\begin{array}{c}\text { No } \\
\text { Migration }\end{array}$ & $\begin{array}{c}\text { W/ Baseline } \\
\text { Migration }\end{array}$ & $\begin{array}{c}\text { Driving } \\
\text { Channel }\end{array}$ \\
\hline$\% \Delta$ population & 0 & $\mathbf{1 1 . 7}$ & $\uparrow w_{m}$ \\
$\% \Delta N_{a}$ & 32.1 & $\mathbf{4 0 . 7}$ & $\downarrow \hat{\eta}$ \\
$\% \Delta N_{r}$ & -24.1 & $\mathbf{- 1 3 . 3}$ & $\downarrow \eta^{*}$ \\
$\% \Delta L_{s, \text { natives }}$ & 3.6 & $\mathbf{- 7 . 5}$ & $\downarrow \hat{\eta}, \eta^{*}$ \\
$\% \Delta w_{a}$ & 13.2 & $\mathbf{1 3 . 4}$ & $L_{a}, K$ complements \\
$\% \Delta w_{r}$ & 12.0 & $\mathbf{1 1 . 4}$ & $\uparrow L_{r}$ \\
$\% \Delta w_{s}$ & 17.8 & $\mathbf{0 . 0}$ & $\uparrow m i g$ \\
$\% \Delta K$ & 167.5 & $\mathbf{1 7 5 . 7}$ & $L_{a}, K$ complements \\
$\% \Delta A g U t i l i t y_{\text {natives }}$ & 2.1 & $\mathbf{1 6 . 6}$ & $\downarrow \hat{\eta}, \eta^{*}, \uparrow K$ \\
\hline \hline
\end{tabular}




\section{Online Appendix - Not for Publication}

\section{A1. Additional Summary Statistics}

Table A1: Top 10 Occupations by Task Supply Index in 1980

\begin{tabular}{|c|c|c|c|c|}
\hline & Occupations & Analytical & Routine & Manual \\
\hline \multicolumn{5}{|c|}{ Panel A. Top Analytical Occupations } \\
\hline 1 & Funeral directors & 0.990 & 0.000 & 0.010 \\
\hline 2 & Atmospheric and space scientists & 0.990 & 0.000 & 0.010 \\
\hline 3 & Writers and authors & 0.976 & 0.000 & 0.024 \\
\hline 4 & Dietitians and nutritionists & 0.876 & 0.115 & 0.009 \\
\hline 5 & Lawyers & 0.847 & 0.129 & 0.024 \\
\hline 6 & Buyers, wholesale and retail trade & 0.800 & 0.057 & 0.143 \\
\hline 7 & Bill and account collectors & 0.800 & 0.173 & 0.027 \\
\hline 8 & Advertising and related sales jobs & 0.798 & 0.180 & 0.022 \\
\hline 9 & Clergy and religious workers & 0.771 & 0.031 & 0.198 \\
\hline 10 & Marketing managers & 0.760 & 0.074 & 0.165 \\
\hline \multicolumn{5}{|c|}{ Panel B. Top Routine Occupations } \\
\hline 1 & Proofreaders & 0.032 & 0.952 & 0.016 \\
\hline 2 & Motion Picture Projectionists & 0.156 & 0.835 & 0.009 \\
\hline 3 & Meter readers & 0.227 & 0.760 & 0.013 \\
\hline 4 & File clerks & 0.118 & 0.735 & 0.147 \\
\hline 5 & Typists & 0.156 & 0.719 & 0.125 \\
\hline 6 & Butchers and meat cutters & 0.294 & 0.696 & 0.010 \\
\hline 7 & Cashiers & 0.248 & 0.657 & 0.095 \\
\hline 8 & Precision grinders and filers & 0.133 & 0.655 & 0.212 \\
\hline 9 & Secretaries & 0.301 & 0.654 & 0.046 \\
\hline 10 & Payroll and timekeeping clerks & 0.340 & 0.653 & 0.007 \\
\hline \multicolumn{5}{|c|}{ Panel C. Top Manual Occupations } \\
\hline 1 & Parking lot attendants & 0.000 & 0.000 & 1.000 \\
\hline 2 & Garbage and recyclable material collectors & 0.000 & 0.000 & 1.000 \\
\hline 3 & Water transport infrastructure tenders and crossing guards & 0.044 & 0.000 & 0.956 \\
\hline 4 & Crossing guards and bridge tenders & 0.044 & 0.000 & 0.956 \\
\hline 5 & Law enforcement (e.g., sheriffs, etc.) & 0.095 & 0.036 & 0.869 \\
\hline 6 & Bus drivers & 0.160 & 0.008 & 0.832 \\
\hline 7 & Housekeepers, maids, butlers, stewards, and lodging quarters cleaners & 0.083 & 0.115 & 0.802 \\
\hline 8 & Taxi cab drivers and chauffeurs & 0.129 & 0.073 & 0.798 \\
\hline 9 & Waiter/waitress & 0.196 & 0.071 & 0.732 \\
\hline & Guards, watchmen, doorkeepers & 0.128 & 0.149 & 0.723 \\
\hline
\end{tabular}


Table A2: Top 15 Commuting Zones by predicted PC adoption, 1980-2010

\begin{tabular}{llcc}
\hline \hline & Commuting & State & $\begin{array}{c}\text { Predicted } \\
\text { PC use }\end{array}$ \\
\hline 1. & DC & Washington DC & 62.7 \\
2. & CA & San Jose & 59.2 \\
3. & NY & New York & 58.8 \\
4. & MA & Boston & 58.4 \\
5. & NJ & Newark & 58.2 \\
6. & AZ & Santa Fe & 58.2 \\
7. & TX & Austin & 58.2 \\
8. & CT & Bridgeport & 58.2 \\
9. NY & Union & 58.1 \\
10. & CA & San Francisco & 58.0 \\
11. KS & Wichita & 57.9 \\
12. NY & Poughkeepsie & 57.6 \\
13. IL & Springfield & 57.4 \\
14. & MN & Minneapolis & 57.4 \\
15. & TX & Dallas & 57.4 \\
\hline \hline
\end{tabular}

Note: The table lists the top $15 \mathrm{CZs}$ in terms of the PC use as predicted by our proxy measure in the period 1980-2010. The lists include large local labor markets that host universities (e.g., Austin, Boston) or high-tech and research corporations and laboratories (e.g., IBM in Poughkeepsie; Los Alamos Laboratories in Santa Fe) or both (e.g., New York, San Jose).

Table A3: US and Foreign Born Non-Employment and PC Adoption, 1980-2010

\begin{tabular}{|c|c|c|c|c|}
\hline & $(1)$ & $(2)$ & $(3)$ & $(4)$ \\
\hline & \multicolumn{4}{|c|}{ US low-skill FB low-skill US high-skill FB high-skil } \\
\hline \multirow[t]{2}{*}{ PC Use } & -0.579 & $-0.905^{*}$ & $-2.951^{* * *}$ & $-1.117^{* * *}$ \\
\hline & $(0.475)$ & $(0.356)$ & $(0.694)$ & $(0.243)$ \\
\hline Obs. & 722 & 722 & 722 & 722 \\
\hline
\end{tabular}

Note: The sample is composed of $722 \mathrm{CZs}$ observed between 1980 and 2010 $(\mathrm{N}=722)$. Standard errors (in parentheses) are clustered at the state level. All regressions are weighted by the beginning of decade $\mathrm{CZ}$ population. Each column reports the $\beta \mathrm{s}$ from equations (2) and (3) where the outcome variable is $\frac{n o n-E m p l_{c, t}^{h}-n o n-E m p l_{c, t-30}^{h}}{n o n-E m p l_{c, t-30}^{h}}$ for native and foreign born population. All regressions include a constant and state fixed effects.

$* *, * *,+$ indicate significance at 1-percent, 5-percent and 10-percent level, respectively. 


\section{A2. Simulation Figures: Robustness Exercises}

Finally, we note that the basic findings of the theory are quite robust to parameterization. Essentially, what we require is that analytical labor and the capital-routine labor aggregate are grossly complementary $(\beta<0)$, routine labor and capital are grossly substitutable $(\gamma>0)$, goods and services are grossly complementary in utility $(\sigma>0)$, and analytical workers are more productive than routine workers in production $\left(\alpha_{a}>1\right)$. Each assumption remains uncontroversial in the literature.

We can however adjust parameters to observe quantitative changes to our baseline results. How our results change, either positively or negatively, are displayed in Figures A1 - A6. Note that each parameter change creates a change both to the initial values of the variables ("shift") and to their growth paths as computer capital growth occurs ("over time"). But patterns discussed in the paper remain basically consistent.

Table A4: Simulation Results - Baseline Parametrization

\begin{tabular}{lll}
\hline \hline Variables & $\begin{array}{l}\text { No } \\
\text { Migration }\end{array}$ & $\begin{array}{l}\text { Migration } \\
\text { Baseline }\end{array}$ \\
\hline$\% \Delta$ population & 0 & $\mathbf{6 . 5}$ \\
$\% \Delta N_{a}$ & 14.1 & $\mathbf{1 5 . 7}$ \\
$\% \Delta N_{r}$ & -21.2 & $\mathbf{- 1 4 . 4}$ \\
$\% \Delta N_{s, n a t i v e s}$ & 9.6 & $\mathbf{2 . 3}$ \\
$\% \Delta w_{a}$ & 9.6 & $\mathbf{1 0 . 2}$ \\
$\% \Delta w_{r}$ & 1.7 & $\mathbf{- 0 . 9}$ \\
$\% \Delta w_{s}$ & 14.7 & $\mathbf{2 . 1}$ \\
$\% \Delta K$ & 272.0 & $\mathbf{2 7 4 . 5}$ \\
$\% \Delta Y_{g}$ & 21.8 & $\mathbf{2 4 . 2}$ \\
$\% \Delta e$ arning $s_{\text {natives }}$ & 18.9 & $\mathbf{1 8 . 2}$ \\
\hline \hline
\end{tabular}

Note: Baseline parameters set to the following: $\gamma=0.5, \beta=-10$, $\sigma=0.5, \rho=0.5, \alpha_{a}=1.75, p_{a}=0.25, p_{m}=0.5, \phi=2, \epsilon_{s}=$ 30. This produces initial employment levels of $N_{a}=0.27, N_{r}=$ 0.35 , and $N_{s}=0.38$. Furthermore, changes in values for $p_{a}, p_{m}$ and between 0.1 and 1 keep changes in quantities close to baseline results. 


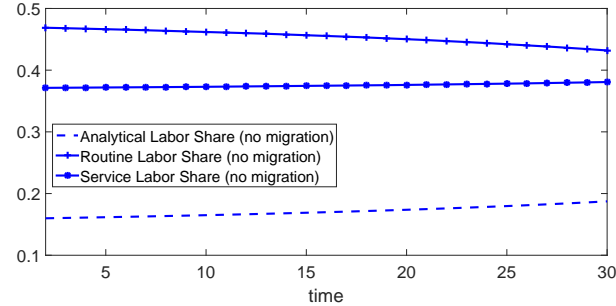

(a) Natives employment levels

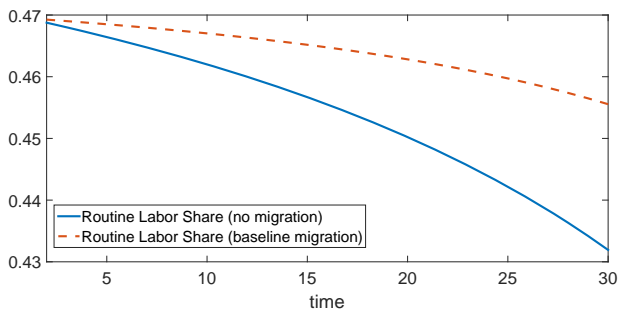

(c) Native routine employment

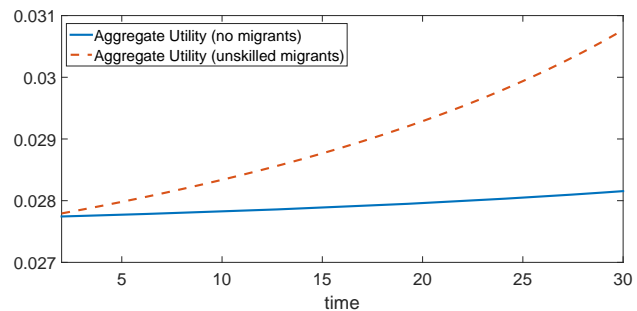

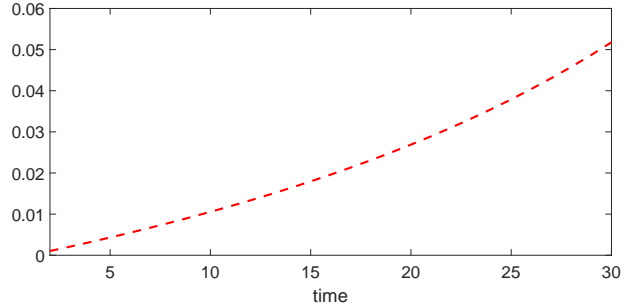

(b) Unskilled migration

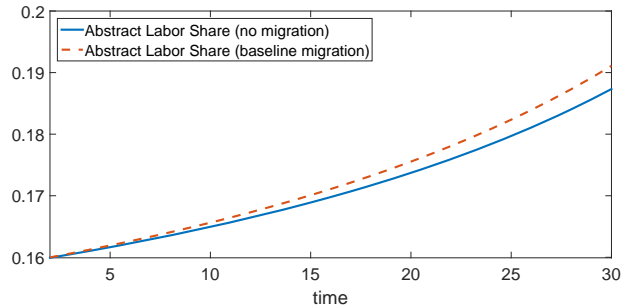

(d) Native analytical employment

(e) Aggregate native utility

Figure A1: Robustness exercise: Less complementarity between skilled labor and capital $(\beta \uparrow$ to -1$)$ 


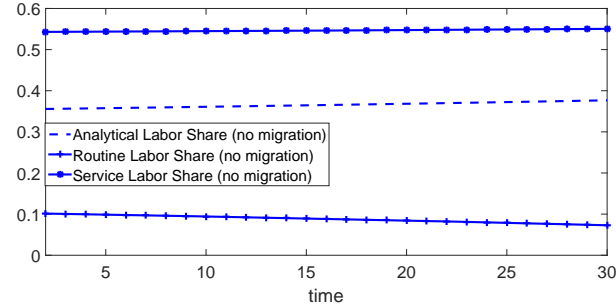

(a) Natives employment levels

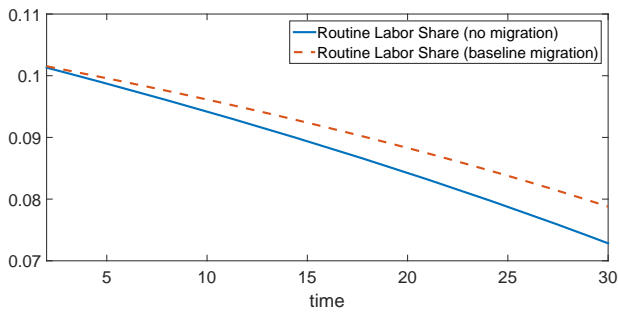

(c) Native routine employment

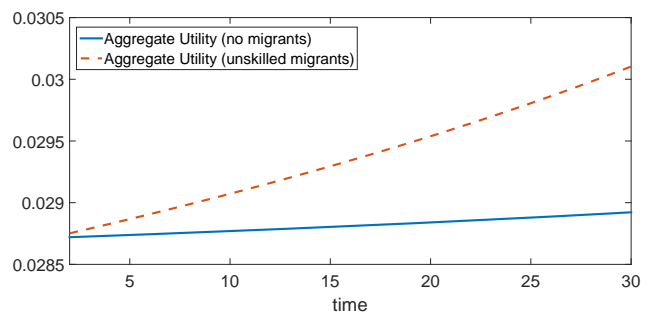

(e) Aggregate native utility

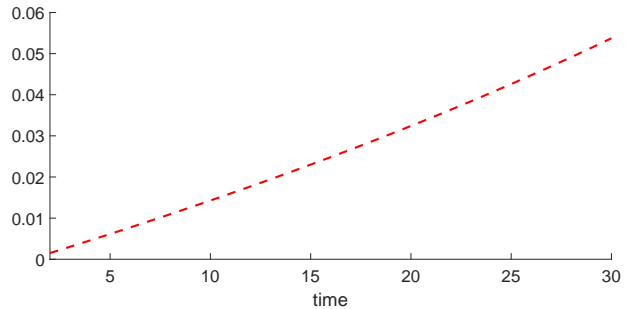

(b) Unskilled migration

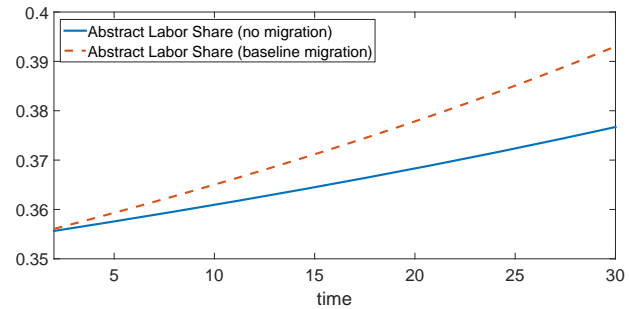

(d) Native analytical employment

Figure A2: Robustness exercise: Less substitutability between routine labor and capital $(\gamma \downarrow$ to 0.25$)$ 


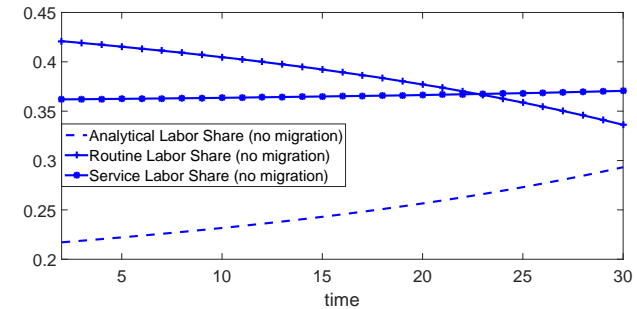

(a) Natives employment levels

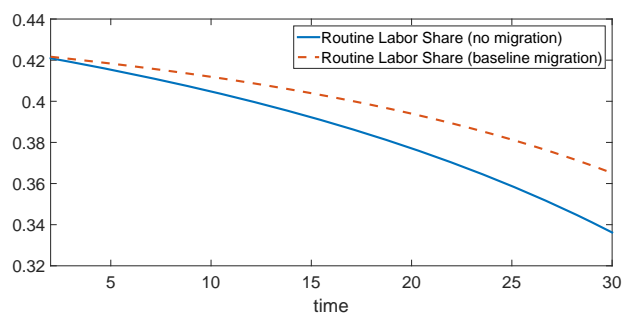

(c) Native routine employment

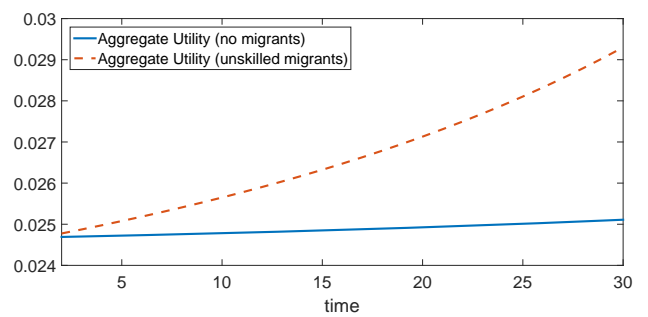

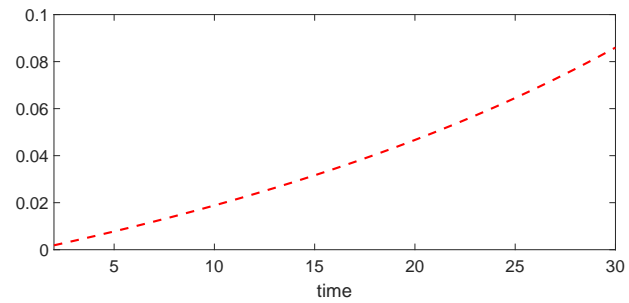

(b) Unskilled migration

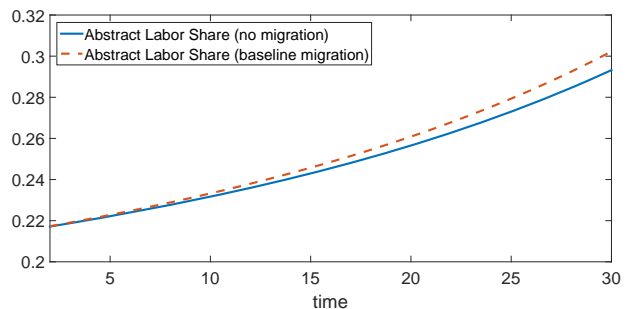

(d) Native analytical employment

(e) Aggregate native utility

Figure A3: Robustness exercise: Less complementarity between goods and services in utility ( $\sigma \uparrow$ to 0.75 ) 


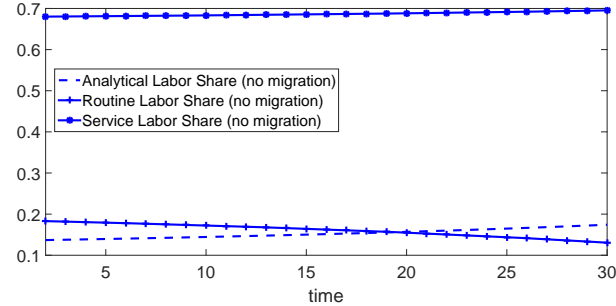

(a) Natives employment levels

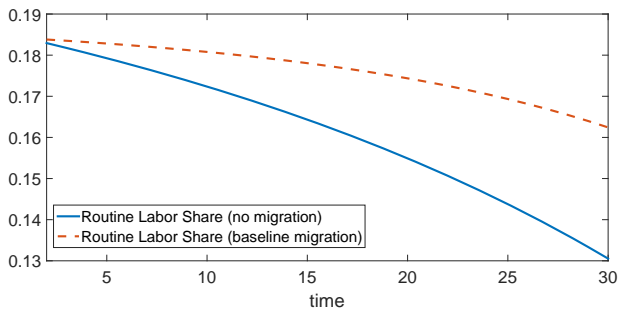

(c) Native routine employment

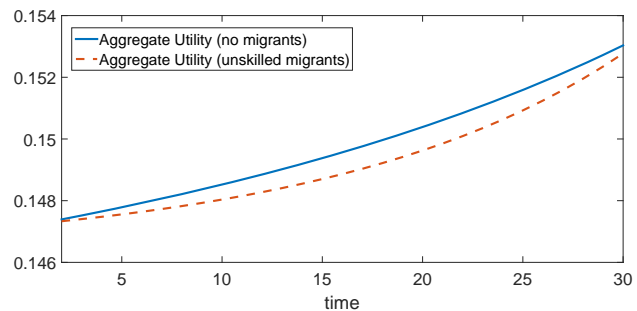

(e) Aggregate native utility

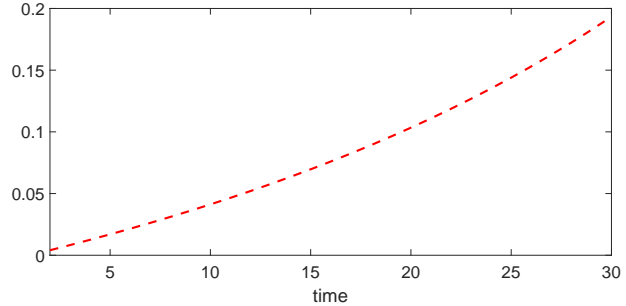

(b) Unskilled migration

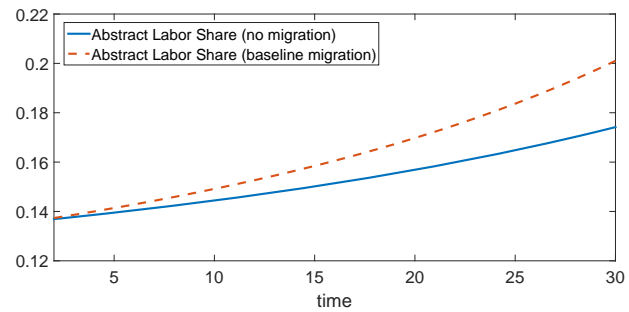

(d) Native analytical employment

Figure A4: Robustness exercise: Greater weight on services in utility ( $\rho \uparrow$ to 0.4 ) 


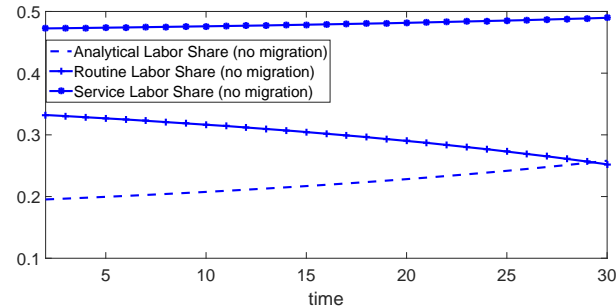

(a) Natives employment levels

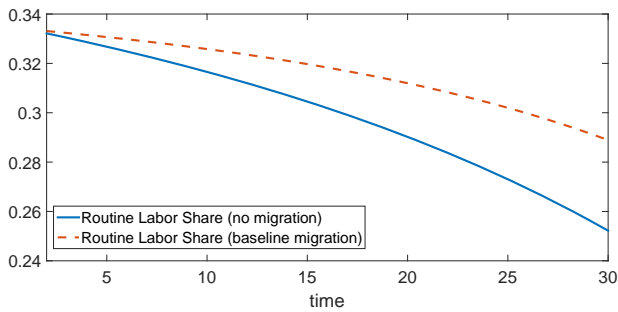

(c) Native routine employment

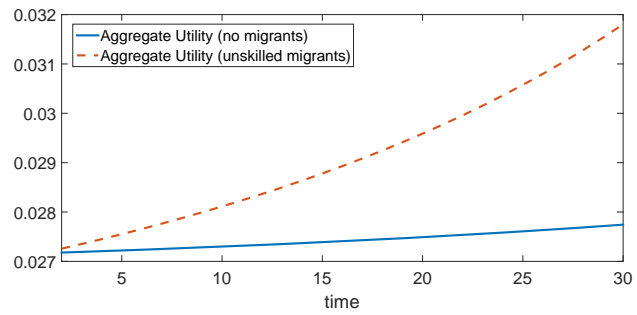

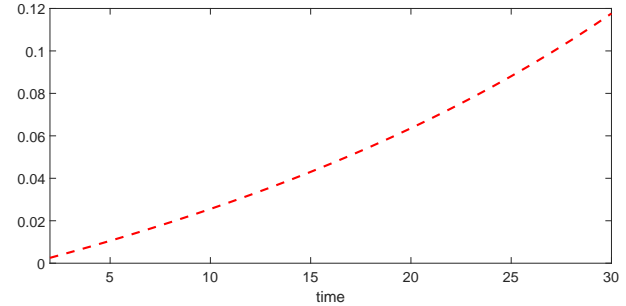

(b) Unskilled migration

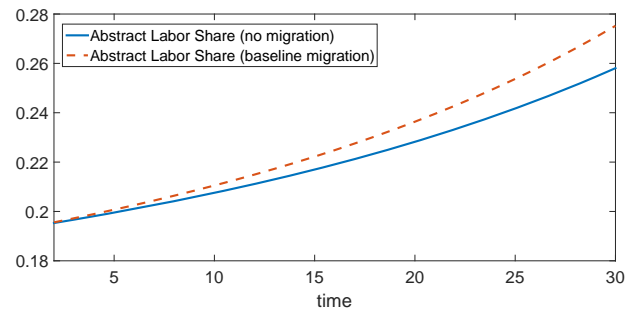

(d) Native analytical employment

(e) Aggregate native utility

Figure A5: Robustness exercise: Greater response of migrants to wage increase $\left(\epsilon_{s} \uparrow\right.$ to 25 


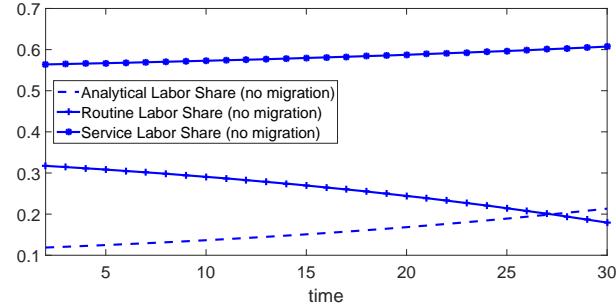

(a) Natives employment levels

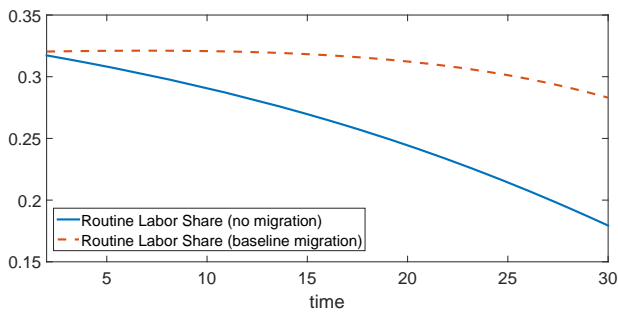

(c) Native routine employment

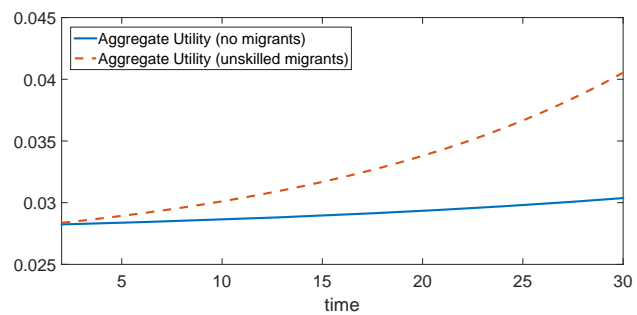

(e) Aggregate native utility

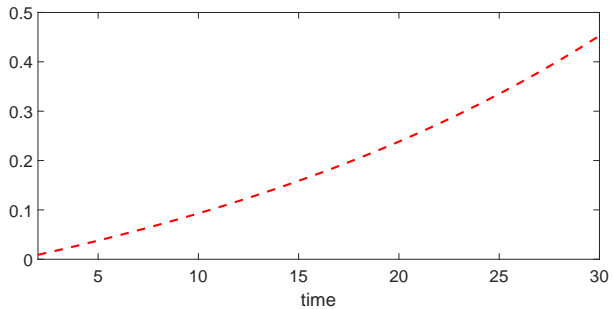

(b) Unskilled migration

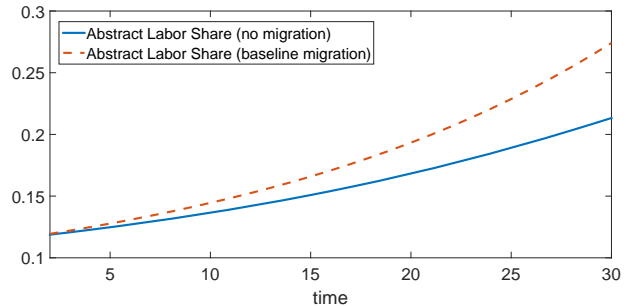

(d) Native analytical employment

Figure A6: Robustness exercise: Greater response of migrants to wage increase $\left(\epsilon_{s} \uparrow\right.$ to 26 


\section{A5. Equilibrium of Simplified Model - Two Forms of Labor and Exogenous Unskilled Migration}

In this section we describe a simplified version of the full model. We do this to show some analytical and straight-forward solutions, as well as to demonstrate that our basic findings are consistent even in this more restrictive case.

Consider then the case of just two forms of labor - analytical and manual; there is no routine labor (one can imagine an extreme case where routine labor and capital are perfectly substitutable, with capital the more productive factor. Routine labor then has become completely obsolete.). Utility is still given by:

$$
\left(\rho C_{s}^{\frac{\sigma-1}{\sigma}}+(1-\rho) C_{g}^{\frac{\sigma-1}{\sigma}}\right)^{\frac{\sigma}{\sigma-1}},
$$

and consumption of services and goods have the same forms as before:

$$
\begin{gathered}
C_{s}=Y_{s}=L_{s}, \\
C_{g}=Y_{g}-p_{k} K-p_{a} L_{a},
\end{gathered}
$$

where $Y_{s}$ is total production of services, $Y_{g}$ is total production of manufactured goods, $p_{k}$ is the price of capital, and $p_{a}$ is the price of analytical skills. Natives now only have two options: they can be a manual worker, or they can pay $p_{a}$ to employ their analytical skills in manufacturing. Production in manufacturing here takes the simple Cobb-Douglas form:

$$
Y_{g}=\left(\alpha_{a} L_{a}\right)^{\alpha} K^{1-\alpha} .
$$

Analytical skill is exponentially distributed as before, and total analytical labor is still given by: 


$$
L_{a}=(\hat{\eta}+1) e^{-\hat{\eta}},
$$

and the threshold amount of skill $(\hat{\eta})$ is given by equating the return to analytical skilled labor and the return to manual labor for the threshold-individual:

$$
w_{a} \hat{\eta}-p_{a}=w_{s} .
$$

As usual, labor-types and capital are paid their marginal products. Finally, potential migrants are all unskilled, and contribute to the mass of manual workers. This mass is thus given by

$$
L_{s}=1+m i g-e^{-\hat{\eta}}
$$

\section{Comparative Statics}

We wish to understand factors that may lead natives to increase or decrease skills. The wage for these skills is given by

$$
w_{a}=\alpha\left(\alpha_{a} L_{a}\right)^{\alpha-1} K^{1-\alpha} .
$$

The price of capital, exogenously given, must equal the marginal productivity of capital:

$$
p_{k}=(1-\alpha)\left(\alpha_{a} L_{a}\right)^{\alpha} K^{-\alpha} .
$$

Combining these and simplifying then gives us

$$
w_{a}=\alpha(1-\alpha)^{\frac{1-\alpha}{\alpha}} p_{k}^{\frac{\alpha-1}{\alpha}} .
$$

Right away, we see that the analytical wage is pinned down strictly by the price 
of capital. As capital prices fall, the return on analytical skills rises. Notice also that this implies there is no impact from unskilled immigration on analytical wages. More on this below.

Unskilled immigration on the other hand is predicted to lower the unskilled wage. To see this note that we can rearrange (A6), substitute in (A10), and get:

$$
\hat{\eta}=\frac{\left(w_{s}+p_{a}\right) p_{k}^{\frac{1-\alpha}{\alpha}}}{\alpha(1-\alpha)^{\frac{1-\alpha}{\alpha}}} .
$$

We can take this expression and plug it into (A7) to solve for $w_{s}$ :

$$
w_{s}=\frac{-\alpha(1-\alpha)^{\frac{1-\alpha}{\alpha}} \ln \left(m i g+1-L_{s}\right)}{p_{k}^{\frac{1-\alpha}{\alpha}}}-p_{a}
$$

Finally, we have some simple comparative statics to suggest.

Proposition 1. $\frac{\partial \hat{\eta}}{\partial p_{k}}>0$.

This is clear from equation (A11). It means that falling capital prices will result in falling levels of $\hat{\eta}$, which means more analytical labor in equilibrium. Capital growth spurs education.

Proposition 2. $\frac{\partial \hat{\eta}}{\partial m i g}=\left(\frac{\partial \hat{\eta}}{\partial w_{s}}\right)\left(\frac{\partial w_{s}}{\partial m i g}\right)<0$.

The first term being positive is clear from (A11); the second term being negative is clear from (A12). It means that exogenous increases in unskilled migration results in a falling education threshold, which means more analytical labor in equilibrium. Immigration spurs education.

Proposition 3. $\frac{\partial^{2} \hat{\eta}}{\partial p_{k} \partial m i g}=\left(\frac{\partial\left(\frac{\partial \hat{\eta}}{\partial p_{k}}\right)}{\partial w_{s}}\right)\left(\frac{\partial w_{s}}{\partial m i g}\right)<0$.

Again, the first term being positive is clear from (A11); the second term being negative is clear from (A12). This suggests that skill enhancements from technological progress are accelerated with unskilled migration. Technological progress and migration together spur education increases even more. 
The key takeaway here is that unskilled migration spurs greater human capital accumulation without hurting the earnings of those with human capital. The reason is that the marginal productivity of capital here is pinned down by the price of capital, which is exogenously given. As migrants push natives to higher levels of education, it raises the productivity of capital, which spurs capital growth, pushing analytical wages back up.

\section{Relation to Conclusions from Main Model}

So how does the simple theory here compare to the full theory described earlier? This simple model cannot comment on certain points raised by the general theory, since there is no possibility of polarization in this economy, and immigration is treated exogenously. However, it does echo points $3-5$.

Specifically, immigration is shown to drive natives up the skill distribution, away from manual tasks and toward analytical tasks. Further, we know from the general model that the negative impacts on native wages from migration are mitigated, or even reversed, from the growth in capital that such migration fosters. In this simplified case this suggestion is even more stark. Given (A10) skilled wages are altogether unaffected by migration, so we find that the total earnings for skilled natives must rise (greater supply of skills with same wage) with greater migration.

The more generalizable model points to the fact that unskilled immigration is a benefit to middle-income Americans. The simple model here points to something related - unskilled immigration is a benefit to those with at least some skills.

\section{B. Data Appendix}

The data used to construct our dependent and independent variables are drawn from the US Census public use microdata as available from IPUMS (Ruggles et al. 2015) and the US Bureau of Economic Analysis Input-Output Tables. We 
use Census microdata from 1950, 1970 (aggregating two 1\% metropolitan area samples), 1980, 1990 and 2000 (5\% samples), as well as the 2009-2011 American Community Survey, which creates a 3\% sample around 2010 that we use for that year. We include in our sample all individuals age 18-65 not residing in group quarters and not enrolled in school. We define employed an individual who worked a positive amount of hours and had positive income from wages in the previous year, excluding thus self-employed and unpaid family workers. Wages are measured as the logarithm of weekly wages that we define as the total income from wages divided by weeks worked in the previous year. All the dollar amounts are expressed in $\$$ as of 2010 adjusted using the BLS CPI-U All Items. The samples are weighted by the product of the Census personal weight.

We define foreign born, or immigrants, all the individuals who are born abroad (outside US territories), including those who become naturalized citizens. We define low-skilled workers (or "high school or less") as those with either 12 completed years of schooling and/or a high school or equivalent diploma, and as highskilled workers (or "college or more") those with at least one year of college or more. Following Autor and Dorn (2013), we define occupations based on the IPUMS variable OCC1990, aggregating the classification in order to construct a consistent set for the entire sample period. We construct the three group of occupations, managerial/professional/technicians, clerical/sales/operators, and services/construct/transp, further aggregating up the occupations following Autor and Dorn (2013). To construct the task specialization measure we match each of the 330 occupation categories to the intensity of manual, routine and analytical tasks performed on the job as described by the 1977 BLS Dictionary of Occupational Titles (Autor and Dorn, 2013). We directly use these measures to construct three indexes of task specialization which represent the percentiles of each occupation in the distribution of occupations ranked by task in 1980 (weighted by 1980 occupational employment). Each worker, therefore, has an index that reflects her 
specialization in analytical, routine and manual tasks, which we then aggregate by Census year and Commuting Zone. Table A1 lists the ten occupations with the highest value of each task intensity index as of 1980 .

We use as main geographical unit of analysis 722 Commuting Zones that encompass the 48 adjoining US states, thus dropping Alaska and Hawaii. Commuting Zones are clusters of counties that are characterized by strong within-cluster and weak between-cluster commuting ties, thus capturing the boundaries of local labor markets (Tolbert and Sizer, 1996; Autor and Dorn, 2013; Basso and Peri, 2016). In order to match the geographic information contained in the IPUMS data (SEA in the 1950 Census, County Group in the 1970 and 1980 Census, PUMA in the 1990 and 2000 Census, and in the 2009-2011 ACS) to Commuting Zones we use the crosswalk developed by Autor and Dorn (2013) (as available on David Dorn's website, http://www.ddorn.net/data.htm). Hence we multiply the person weights described above with an adjustment factor that accounts for the fraction of a SEA/County Group/PUMA that maps to a given Commuting Zone. 